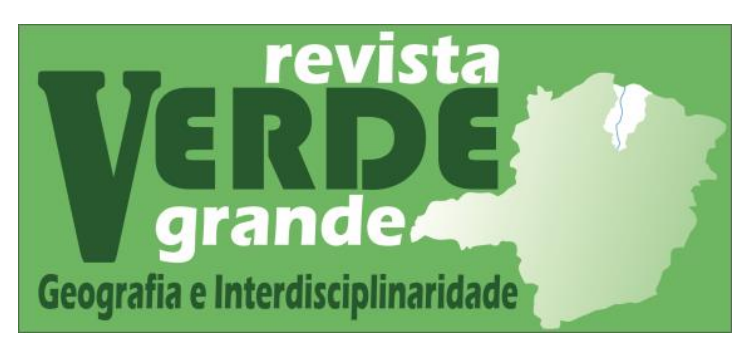

Volume 2, no. 2 (2020)

ISSN: 2675-2395

https://doi.org/10.46551/rvg26752395202022855

\title{
VULNERABILIDADE NATURAL À PERDA DE SOLO DA MICROBACIA HIDROGRÁFICA DO RIO CARNAÍBA DE DENTRO, SEMIÁRIDO BAIANO
}

\section{Natural vulnerability to loss of soil of the micro-watershed of the Carnaíba de Dentro river, southwest of the semi-arid region of Bahia}

Jardel Gybson Soares Costa ${ }^{1}$ https://orcid.org/0000-0002-6225-7747

Mateus Ribeiro Caetano ${ }^{2}$ https://orcid.org/0000-0002-9436-8249

Carlos Magno Santos Clemente ${ }^{3}$ https://orcid.org/0000-0002-1087-5228

\footnotetext{
${ }^{1}$ Graduando em Engenharia Civil pelo Centro Universitário FG (UNIFG) - Discente pesquisador do Observatório UniFG do Semiárido Nordestino. E-mail: jgsoaresc@gmail.com

${ }^{2}$ Graduando em Engenharia Civil pelo Centro Universitário FG (UNIFG) - Discente pesquisador do Observatório UniFG do Semiárido Nordestino. E-mail: mateusribeirocaetano@gmail.com

${ }^{3}$ Doutorando em Geografia - Tratamento da Informação Espacial pela Pontifícia Universidade Católica de Minas Gerais. Mestre em Geografia pela UNIMONTES. Coordenador do Observatório UniFG do Semiárido Nordestino - Docente do curso de Engenharia Civil do Centro Universitário FG (UNIFG). E-mail: carlosmagno.clemente@ gmail.com
}

\begin{abstract}
Resumo
A presente pesquisa teve como objetivo classificar o grau de vulnerabilidade natural à perda de solo da microbacia hidrográfica do Rio Carnaíba de Dentro (BA), indicando a prevalência dos processos do balanço morfogênese/pedogênese. A área de estudo localiza-se no contexto regional do sudoeste do Semiárido Brasileiro. Como técnica utilizou-se as Geotecnologias, a fim de realizar a coleta, armazenamento, tratamento, análise espacial e representação dos dados obtidos, da vulnerabilidade à perda de solo da microbacia do Rio Carnaíba de Dentro (BA). Concluiu-se que houve um equilíbrio entre a pedogênese/morfogênese, uma vez que o meio Medianamente Estável/Vulnerável possui maior incidência sobre microbacia do Rio Carnaíba de Dentro (BA), contrariando a hipótese da prevalência dos processos de morfogênse, majoritariamente presentes em todo semiárido brasileiro. Logo, a partir dos dado e informações obtidos é possível fornecer subsídios para um melhor direcionamento na elaboração de políticas públicas para a microbacia do Rio Carnaíba de Dentro (BA).
\end{abstract}

Palavras-chave: Geotecnologias; Ecodinâmica; Erosão.

\begin{abstract}
This research aimed to classify the level of natural vulnerability to soil loss of the Carnaíba de Dentro River micro basin (BA), indicating the prevalence of morphogenesis/pedogenesis balance processes. The study area is located in the southwest of the Semiarid Region of Brazil. Geotechnologies were used as a technique of collection, storage, treatment, spatial analysis, and representation of the obtained data, resulting in vulnerability to soil loss of the Carnaíba de Dentro micro basin (BA). The study concluded there was a balance between the pedogenesis/morphogenesis, since the Moderately Stable/Vulnerable environment has a higher incidence on the Carnaíba de Dentro River watershed (BA), contradicting the hypothesis of the prevalence of morphogenesis processes, mostly found throughout Brazilian semiarid.
\end{abstract}


Vulnerabilidade natural à perda de solo da microbacia hidrográfica do rio Carnaíba de Dentro, Semiárido Baiano

Jardel Gybson Soares Costa; Mateus R. Caetano; Carlos Magno Santos Clemente

Thus, from the data and information obtained, it is possible to provide subsidies for a better guiding in the elaboration of public policies for the Carnaíba de Dentro River micro basin (BA).

Keywords: Geotechnologies; Ecodynamics; Erosion.

\section{Introdução}

Desde os albores as civilizações buscam se estabelecer em locais que disponham dos recursos básicos para sustentação da vida. Neste cenário, os recursos naturais são essenciais, sobretudo a água enquanto recurso natural com grande valor agregado que desempenhou um papel fundamental na sobrevivência das primeiras aglomerações humanas (COSTA, 2017). Em virtude disso, as ocupações antrópicas sobre os espaços geográficos causaram mudanças em regiões, desencadeando a degradação ambiental dessas áreas (ARAÚJO, 2009).

O processo em que o ser humano se torna agente modelador do espaço, ocorre quando as suas atividades impactam de forma direta ou indireta nas características de um dado local, fazendo com que este apresente novas feições que por sua vez altera todo seu ciclo de desenvolvimento (RIBEIRO, 1998). Sendo assim, o solo é um dos elementos dentre os quais a ação humana exerce um impacto direto. Nesse sentido, as modificações antrópicas as quais um solo pode estar submetido podem ser, por exemplo, a prática agrícola e a pecuária, que por medidas abrasivas estão aptas a causarem impactos que desencadeiam na perda de solo através da instabilidade dos agregados e, consequente sedimentação (PIRES; SANTOS; DEL PRETTE, 2008).

Diversos impactos ambientais relacionam-se aos processos erosivos, como inundações e assoreamento dos corpos d'água. Assim, surge a necessidade de observar e atentar-se às bacias hidrográficas, de forma a conferir a elas planejamento e gerenciamentos apropriados para promover uma utilização sustentável dos seus recursos. (SOUZA et al., 2010).

Diante disso, uma maneira adequada para enfrentar os impactos negativos gerados pela perda de solo seria buscar por medidas preventivas (PIRES; SANTOS; DEL PRETTE, 2008). Nesse sentido, deve-se realizar um estudo acerca do espaço geográfico para que possa ser identificado as zonas de risco atuantes sobre tal. Para tanto, tais ações podem ser feitas por meio de mapeamentos dessas áreas, o que, por conseguinte, evidenciará em classes de vulnerabilidade a susceptibilidade dos processos de perda de solo, em que o meio está submetido, em função do conceito da Ecodinâmica (LIMA; REMPEL; ECKHARDT, 2007).Destarte, tal conceito indica um modelo de avaliação integrado da área de estudo, 
Vulnerabilidade natural à perda de solo da microbacia hidrográfica do rio Carnaíba de Dentro, Semiárido Baiano

Jardel Gybson Soares Costa; Mateus R. Caetano; Carlos Magno Santos Clemente

baseado no balanço pedogênese/morfogênese, propiciando sua classificação quanto aos graus de instabilidade (TRICART, 1977).

Com isso, pode-se inferir que no estudo das ciências da Terra, a interação entre os processos de pedogênese e morfogênese atua como um indicador da formação ou degradação do solo. Nesse contexto, quando há uma maior atividade da pedogênese, o perfil de solo tornase mais espesso em função do acumulo de materiais e uma maior diversificação dos horizontes, neste caso, haveria pouca atuação do processo de morfogênese. Em contrapartida, quando há uma maior atividade da morfogênese, ocorre uma acelerada desagregação das partículas sólidas que compõem o solo, assim, os perfis de solo tornam-se rasos podendo até ser eliminados, neste caso, não seria possível o pleno desenvolvimento do processo de pedogênese. (TRICART: KILLIAN, 1979)

Para tanto, a Ecodinâmica procura associar os processos de morfogênese e pedogênese dos meios com a finalidade de classificá-los dentro de uma faixa que pode variar entre estável, intermediária e instável, apontando a vulnerabilidade do espaço analisado. Assim, sob a perspectiva da Ecodinâmica, as áreas em que prevalecem o processo de morfogênese (processos erosivos) são consideradas instáveis, em contrapartida as que predominam a pedogênese (processos formadores de solo) são classificadas como estáveis; já quando há equilíbrio entre os dois processos, a área é vista como de estabilidade intermediária (TRICART, 1977).

Com isso, é possível aferir que mapas de vulnerabilidade natural à perda de solo possuem propensão a servirem como base a vários projetos, como os de gestão ambiental e ordenamento territorial, dada a ausência de políticas estaduais efetivas na conservação das bacias hidrográficas (SOUZA et al., 2010). Vale ressaltar que para elaboração dos mapas de vulnerabilidade natural à perda de solo pode-se fazer o uso das geotecnologias, pois estas atuam como a ferramentas na produção de mapas (FONSENCA, 2008).

De acordo Rosa (2005), as geotecnologias englobam um agrupamento de técnicas que procuram realizar coleta, processamento, análise e a viabilização de informações de carácter geográfico de uma determinada localidade. Essas técnicas desencadeiam-se no Sensoriamento Remoto; Processamento Digital de Imagens (PDI); o Sistema de Informação Geográfica (SIG); o Sistema de Posicionamento Global; a Cartografia Digital; e a Topografia (ROSA, 2013).

Com isso, tem-se que o trabalho em conjunto do sensoriamento remoto e do Geoprocessamento auxiliam na análise dos fenômenos erosivos, contribuindo substancialmente para o subsídio ao ordenamento territorial, uma vez que possuem todos os instrumentos fundamentais para o estudo do espaço territorial. (CREPANI et al., 2001). 
Vulnerabilidade natural à perda de solo da microbacia hidrográfica do rio Carnaíba de Dentro, Semiárido Baiano

Jardel Gybson Soares Costa; Mateus R. Caetano; Carlos Magno Santos Clemente

Diante do exposto, entende-se que a construção de mapas de vulnerabilidade natural a perda de solo permite identificar o grau de susceptibilidade a erosão da região de estudo a partir do balanço Morfogênese/Pedogênese. Nesse sentido, sua elaboração servirá de suporte para tomada de decisões das entidades públicas a respeito dos levantamentos obtidos que contribuem para o planejamento ambiental, promovendo dessa forma, uma queda nas taxas de impactos relacionados à intervenção humana (THOMAS, 2012).

Desse entendimento, o presente trabalho teve como objetivo classificar o grau de vulnerabilidade natural à perda de solo da microbacia hidrográfica do Rio Carnaíba de Dentro (BA), indicando a prevalência dos processos do balanço morfogênese/pedogênese.

\section{Materiais e métodos}

A área do estudo compreende uma particularidade do curso médio da bacia hidrográfica do rio São Francisco, em específico, bacia hidrográfica do rio das Rãs. Desse modo, a área de estudo trata-se da Unidade Territorial Básica ${ }^{1}$ (UTB) da microbacia hidrográfica do Rio Carnaíba de Dentro que compõe a sub-bacia do Rio das Rãs, onde estas integram a bacia hidrográfica do Rio São Francisco que estão inserida na região semiárida brasileira. A microbacia hidrográfica do Rio Carnaíba de Dentro está localizada no sudoeste da Bahia de acordo as seguintes coordenadas $43^{\circ} 11^{\prime} 29^{\prime \prime} \mathrm{O}, 13^{\circ} 58^{\prime} 39^{\prime}$ ' S e $42^{\circ} 28^{\prime} 47^{\prime} \mathrm{O}, 14^{\circ} 32^{\prime} 14^{\prime \prime} \mathrm{S}$, apresentando uma área total de $2.576,53 \mathrm{~km}^{2}$ conforme a figura 1.

\footnotetext{
${ }^{1}$ A UTB determina um ecossistema de informações padronizadas e homogêneas, acerca do uso e ocupação do solo, da classificação da cobertura vegetal, dos dados climáticos, bem como das características dos meios físicos Geologia, Geomorfologia e Pedologia (CREPANI et al., 2001).
} 
Vulnerabilidade natural à perda de solo da microbacia hidrográfica do rio Carnaíba de Dentro, Semiárido Baiano

Jardel Gybson Soares Costa; Mateus R. Caetano; Carlos Magno Santos Clemente

Figura 1 - Localização da Microbacia Hidrográfica do Rio Carnaíba de Dentro no Semiárido Baiano

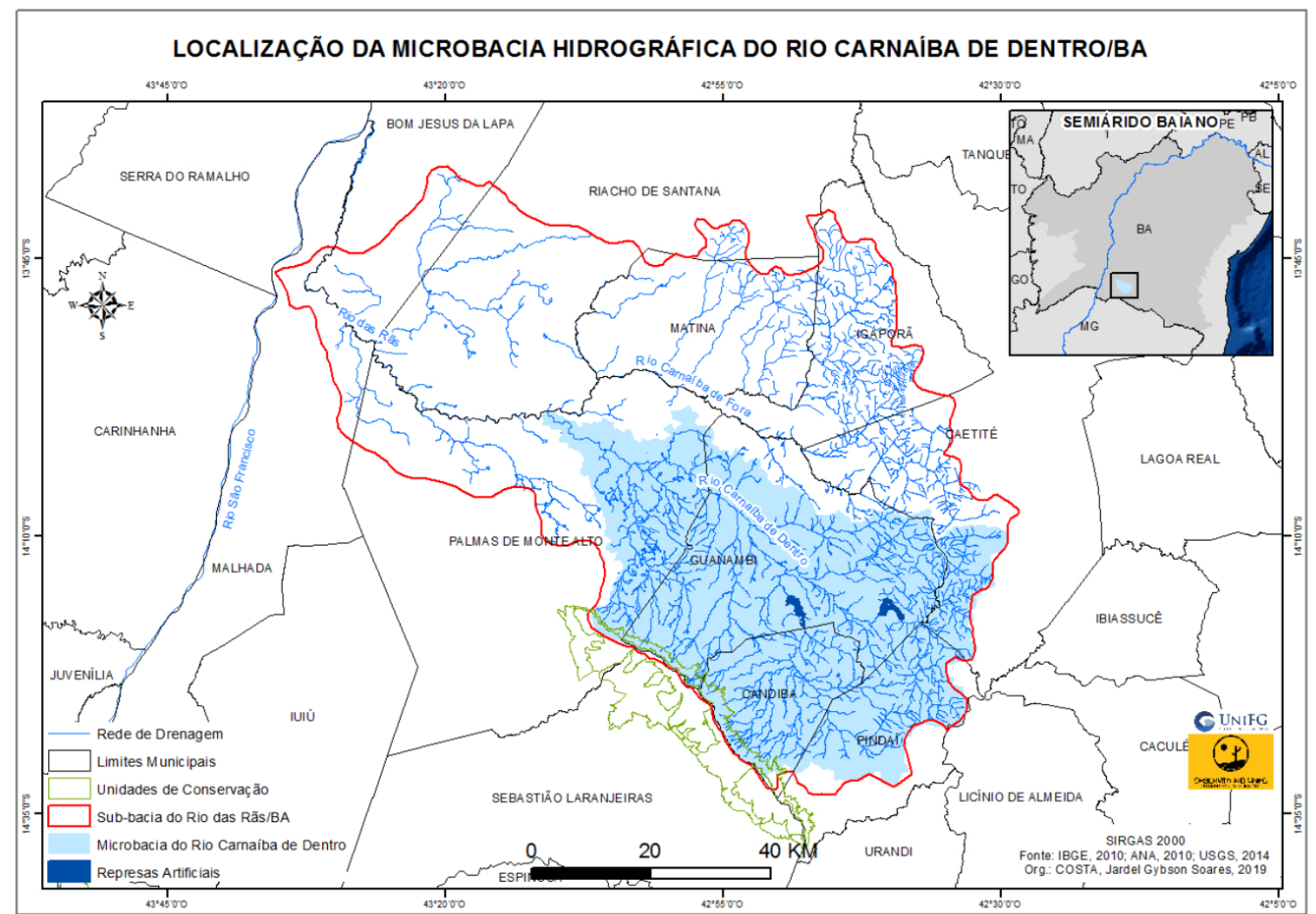

Fonte: IBGE, 2010; ANA, 2010; USGS, 2014

Org.: COSTA, Jardel Gybson Soares, 2019

Para a construção da presente pesquisa foram adotadas as etapas metodológicas desenvolvidas por CREPANI e colaboradores (2001), à luz do conceito da Ecodinâmica de TRICART (1977), que se baseia na relação entre os processos de Morfogênese e Pedogênese. Com isso, a presente metodologia sugere que a avaliação dos parâmetros analisados seja feita de forma integrada, relacionando os aspectos biológicos, físicos e antrópicos, que conferem à paisagem características que a fazem comportar como uma mescla de elementos inseparáveis (AMARAL; ROSS, 2009).

Nesse sentido, para a execução do presente projeto de pesquisa adotou-se três etapas metodológicas, como versa na Figura 2. 
Vulnerabilidade natural à perda de solo da microbacia hidrográfica do rio Carnaíba de Dentro, Semiárido Baiano

Jardel Gybson Soares Costa; Mateus R. Caetano; Carlos Magno Santos Clemente

Figura 2 - Etapas metodológicas

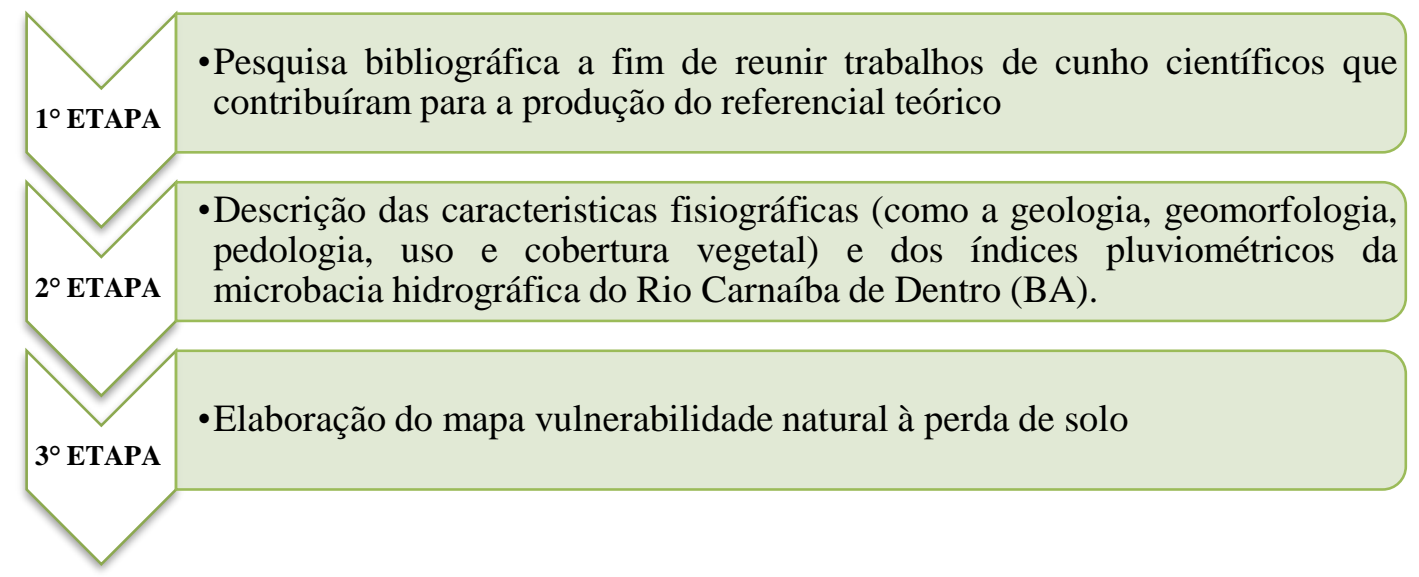

Org.: Autores, 2019

Na primeira etapa foi realizada uma pesquisa bibliográfica a fim de reunir trabalhos de cunho científico que contribuíram para a produção do referencial teórico com autores que discorrem sobre a temática do trabalho, tais como: CREPANI et al., 2001, TRICART, 1977, ROSA, 2005, BECKER; EGLER, 1996; entre outros. Neste contexto, foram abordados os seguintes eixos centrais: vulnerabilidade natural à perda de solo e o planejamento ambiental; geotecnologias; bacia hidrográfica e sua susceptibilidade aos impactos ambientais. Sequencialmente, utilizou-se técnicas como o Sensoriamento Remoto, o Sistema de Informação Geográfica (SIG) e o Processamento Digital de Imagens (PDI) para a segunda, e terceira.

Com isso, os dados necessários para o desenvolvimento desse estudo foram coletados de forma gratuita através de órgãos governamentais brasileiros e internacionais. Sendo estes encontrados em portais eletrônicos de agências como Instituto Brasileiro de Geografia e Estatística (IBGE), Instituto Nacional de Pesquisas Espaciais (INPE), Instituto Nacional de Meteorologia (INMET), Agência Nacional de Águas (ANA), Instituto Estadual do Meio Ambiente e Recursos Hídricos (INEMA) e United States Geological Survey (USGS).

A segunda etapa consistiu na descrição da caracterização fisiográfica (como a geologia, geomorfologia, pedologia, uso e cobertura vegetal) e dos índices pluviométricos da microbacia hidrográfica do Rio Carnaíba de Dentro (BA). Em função disso, fez-se necessário a obtenção dos materiais requeridos para produção dos mapas de caraterização de cada um desses temas.

Foram utilizados os dados do Shuttle Radar Topography Mission (SRTM), com resolução espacial reamostradas à 30 metros, obtidas a partir da grade vetorial no banco de dados United States Geological Survey (USGS), na escala de 1:250.000. Para a delimitação da 
Vulnerabilidade natural à perda de solo da microbacia hidrográfica do rio Carnaíba de Dentro, Semiárido Baiano

Jardel Gybson Soares Costa; Mateus R. Caetano; Carlos Magno Santos Clemente

bacia hidrográfica e a extração da rede de drenagem foram utilizadas ferramentas do software ArcGIS 10.2. $2^{2}$, mais precisamente, o módulo Hidrology Modeling.

Para elaboração do mapa de cobertura vegetal, uso e ocupação do solo, foram utilizados os dados oriundos do sensoriamento remoto, especialmente, do produto Landsat - 8 referentes às órbitas/ponto 218/70 do dia 4 de agosto de 2017. Neste contexto, utilizou-se a classificação supervisionada e o classificador máxima verossimilhança no software Envi $5.5^{3}$, em uma escala de 1:60.000.

Para os mapas temáticos relacionados a geologia, geomorfologia e pedologia, foram utilizados os dados do Instituto Brasileiro de Geografia e Estatística (IBGE) na escala de 1:250.000. Em relação a pedologia, vale ressaltar que existem 6 níveis categóricos em um sistema de classificação de solos, entretanto apenas 4 atualmente possuem definição precisa em seus conceitos. Neste sentido, os níveis categóricos adotados no Sistema Brasileiro de Classificação de Solos (SiBCS) são: $1^{\circ}$ nível (ordem), $2^{\circ}$ nível (subordem), $3^{\circ}$ nível (grande grupo), $4^{\circ}$ nível (subgrupo), $5^{\circ}$ nível (família) e $6^{\circ}$ nível (série). Contudo, foram adotados como critério para caracterização dos solos presentes na bacia os 4 primeiros níveis categóricos, uma vez que estes possuem uma definição precisa acerca de seus conceitos (EMBRAPA, 1999).

Os dados históricos dos índices pluviométricos foram fornecidos pelo Instituto Nacional de Meteorologia (INMET) oriundos de 5 (cinco) estações meteorológicas, estas localizadas dentro e no entorno da microbacia do rio Carnaíba de Dentro (BA). Tais estações estão estabelecidas nos municípios de Bom Jesus da Lapa (BA); Caetité (BA); Carinhanha (BA); Guanambi (BA) e Espinosa (MG), conforme versará a Figura 3.

Os dados fornecidos pelas estações meteorológicas apresentaram um acúmulo de precipitações em uma faixa de 10 (dez) anos, variando em entre os anos 2007 a 2016. Contudo, para adoção da metodologia de Crepani et al, faz-se necessário que tais informações pluviométricas sejam observadas em períodos mensais. Logo, em função do atendimento de tal obrigatoriedade, para evidenciar a média mensal dos indicies pluviométrico considerou-se a quantidade de meses chuvosos distribuídos em toda região do semiárido nordestino no período de um ano.

Diante do exposto, tal premissa foi adotada conforme as acepções de Rebouças (1997), quando afirma que, as chuvas em todo semiárido nordestino, pode ocorrer em 1 (um) mês ou distribuídas de forma irregular de 3-5 meses no ano. Para tanto, adotou-se como critério de obtenção da média dos índices pluviométricos mensais, a distribuição do período chuvoso em

\footnotetext{
2 licenciado pelo Centro Universitário FG - UniFG/Observatório UniFG do Semiárido Nordestino.

${ }^{3}$ licenciado pelo Centro Universitário FG - UniFG/Observatório UniFG do Semiárido Nordestino.
} 
Vulnerabilidade natural à perda de solo da microbacia hidrográfica do rio Carnaíba de Dentro, Semiárido Baiano

Jardel Gybson Soares Costa; Mateus R. Caetano; Carlos Magno Santos Clemente

5 (cinco) meses do ano, uma vez que este valor retrata melhor o período de chuvas presentes na região da microbacia. Nesse sentido, os dados acumulados de precipitações médias anuais, referentes a cada estação, foram divididos por 5 (cinco), quantidade de meses chuvosos, evidenciando assim média dos índices pluviométricos mensais para cada estação.

Em função disso, com o auxílio do método geoestatístico da krigagem ${ }^{4}$ realizou-se a interpolação dos dados de precipitação mensal entre os anos de 2007 a 2016, estabelecendo assim, a intensidade pluviométrica mensal da média destes 10 (dez) anos para uma melhor caracterização do cenário climático da região. Nesse sentido, as interpolações levaram em consideração os dados de precipitações acumuladas, bem como a localização e as distâncias entre as estações (VALERIANO; ROSSETTI, 2012). A Figura 3 apresenta o mapa de localização das estações meteorológicas.

E na terceira e última etapa foi realizada a elaboração do mapa vulnerabilidade natural à perda de solo. A elaboração de mapas de vulnerabilidade natural à perda de solo depende de um conjunto de materiais para sua construção, sendo estes: imagens de satélite, relatórios do Projeto RADAM, bem como os mapas temáticos (Geologia, Geomorfologia, Solos e Uso e Cobertura do Solo) e, dados históricos dos índices pluviométricos (CREPANI, et al., 2001).

Após feitas tais considerações, a microbacia foi analisada e classificada segundo sua instabilidade como já foi mencionado. No entanto, para se obter tais resultados foi aplicado o método de avaliação da estabilidade, que consiste em identificar a vulnerabilidade levando em consideração 21 classes, tais como: valores de 1 a 3, onde são associadas cores aos níveis variantes, no qual a cor azul representa os valores de estabilidade $(1,0)$; a cor verde representa os valores de vulnerabilidade mediana/estável $(2,0)$; a cor vermelha os valores de maior vulnerabilidade (3,0). Esses parâmetros são definidos de acordo ao Figura 4.

\footnotetext{
${ }^{4}$ Tal método procura relacionar as afinidades ou distinções das observações conforme as distâncias no espaço geográfico, isto permite a produção de isolinhas de áreas não observadas (VALERIANO; ROSSETTI, 2012).
} 
Vulnerabilidade natural à perda de solo da microbacia hidrográfica do rio Carnaíba de Dentro, Semiárido Baiano

Jardel Gybson Soares Costa; Mateus R. Caetano; Carlos Magno Santos Clemente

Figura 3: Localização das estações meteorológicas

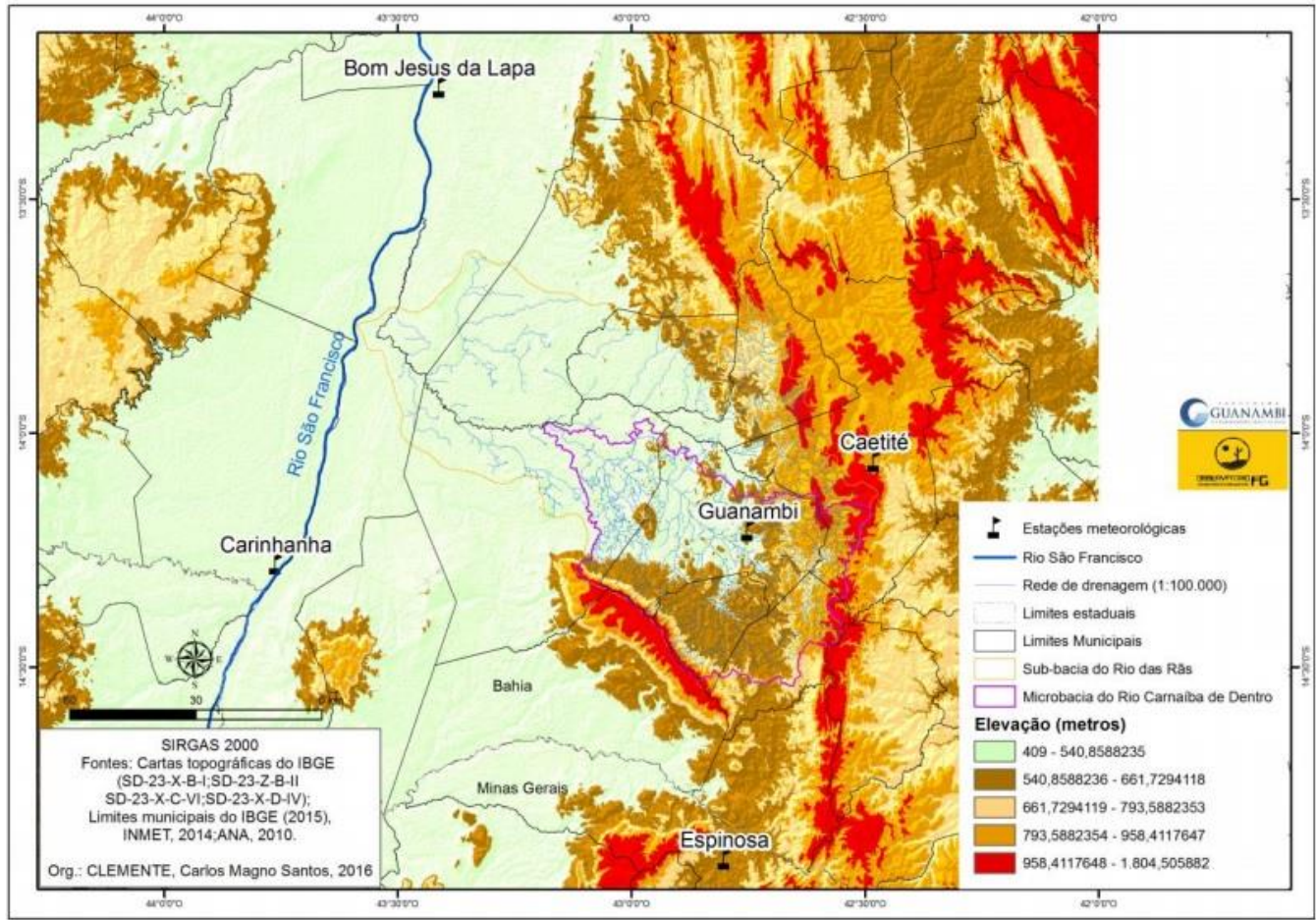

Fonte: CLEMENTE et al, (2016).

Figura 4 - Critérios para determinar o grau de vulnerabilidade de uma UTB

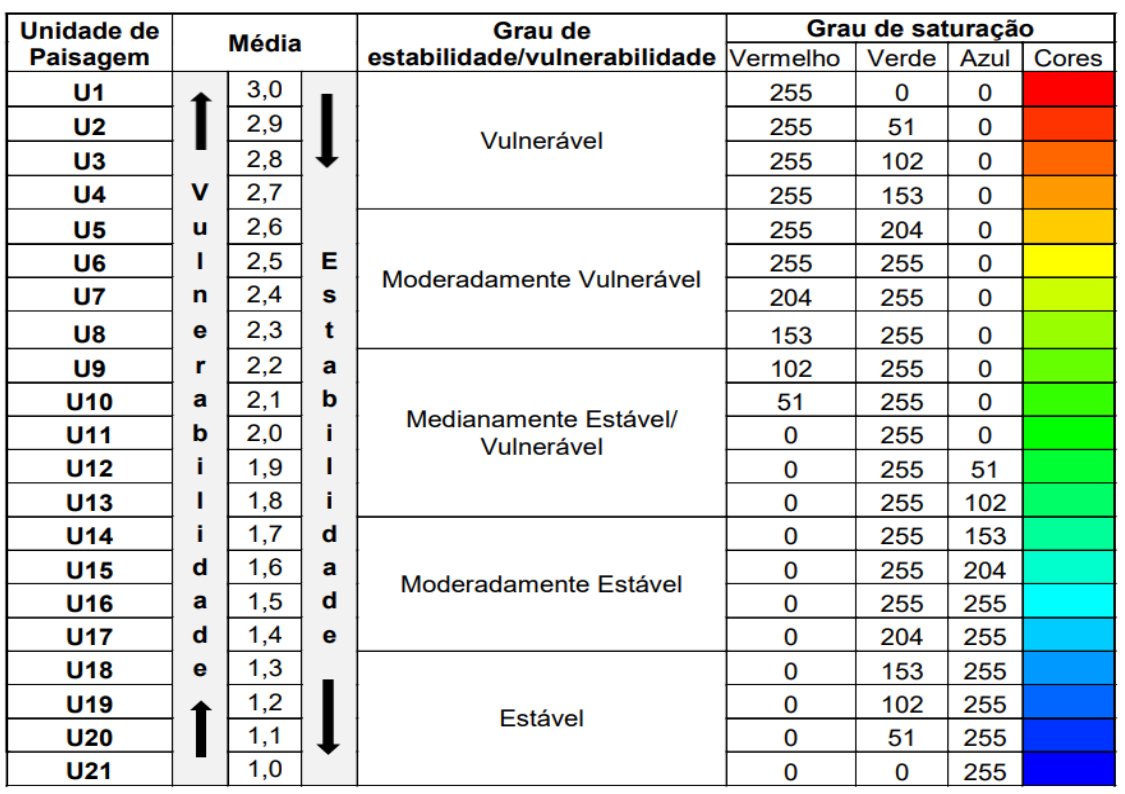

Fonte: CREPANI et.al. (1996).

A construção do mapa de vulnerabilidade natural à perda de solo foi obtida a partir da ponderação feita sobre as varáveis temáticas (Geologia, Geomorfologia, Pedologia, Uso e Cobertura do Solo e o Clima), que promove o cruzamento do balanço Morfogênese/Pedogênese presente em cada um destes temas (CREPANI, et al., 2001). Em função disso, cada variável temática teve um grau de vulnerabilidade associado a suas características, a integração entre 
Vulnerabilidade natural à perda de solo da microbacia hidrográfica do rio Carnaíba de Dentro, Semiárido Baiano

Jardel Gybson Soares Costa; Mateus R. Caetano; Carlos Magno Santos Clemente

eles resulta na vulnerabilidade da microbacia, obtida através do cálculo da média aritmética das ponderações, conforme a Equação 01

$V=\frac{G+R+P+U+C}{5}$

Em que: $\quad \mathrm{V}=$ vulnerabilidade; $\mathrm{G}=$ vulnerabilidade para o tema geologia; $\mathrm{R}=$ vulnerabilidade para o tema geomorfologia; $\mathrm{P}=$ vulnerabilidade para o tema pedologia; $\mathrm{U}=$ vulnerabilidade para o tema uso e cobertura do solo; $\mathrm{C}=$ vulnerabilidade para o tema clima.

Em geral, para cada unidade geológica a média aritmética das ponderações das rochas mais comuns predominantes, assim, apontando o grau de vulnerabilidade presente nas unidades. A partir da caracterização das variáveis intrínsecas a geomorfologia presente na microbacia do Rio Carnaíba de Dentro (BA), identificou-se a vulnerabilidade natural à perda de solo relacionada a este tema. Nesse aspecto, primeiramente foram elaborados dois mapas que retrataram a vulnerabilidade do quadro natural aos fenômenos erosivos levando-se em consideração a declividade e amplitude altimétrica. O cálculo da média aritmética das ponderações, sobre as variáveis declividade e altimetria, resultaram na vulnerabilidade natural à perda de solo do aspecto fisiográfico geomorfológico, que, por conseguinte desembocou em 9 (nove) graus de vulnerabilidade, associados a 5 (cinco) classes. Para os solos foram consideradas os tipos de solos de Embrapa (1973) e as ponderações de Crepani (2001). Em função da caracterização relativa as variáveis climáticas atuantes sobre a microbacia do Rio Carnaíba de Dentro (BA), consideraram as médias dos anos de 2007 a 2016 (INMET), tornouse possível identificar a vulnerabilidade natural à perda de solo associada a tal tema.

\section{Aspectos geológicos, geomorfológicos, dos solos e climático da vulnerabilidade natural à perda de solo}

Historicamente, a humanidade promove a ocupação de territórios, construindo suas civilizações à luz dos recursos naturais. Neste contexto, a água como um recurso natural, que possui um alto valor agregado, se apresenta como um fator fundamental para a sobrevivência da raça humana (COSTA, 2017). Em função disso, ocorreram modificações no espaço geográfico por meio das ocupações antrópicas sobre as áreas de bacias hidrográficas, proporcionando assim, impactos ambientais consideráveis em sua extensão (ARAÚJO, 2009).

Uma bacia hidrográfica atua como um agente geográfico suscetível a impactos ambientais, tanto pelas interferências naturais quanto pela ação antrópica. Sendo assim, essas 
Vulnerabilidade natural à perda de solo da microbacia hidrográfica do rio Carnaíba de Dentro, Semiárido Baiano

Jardel Gybson Soares Costa; Mateus R. Caetano; Carlos Magno Santos Clemente

perturbações ambientais acarretam a descaracterização dos seus aspectos intrínsecos, como: geologia, geomorfologia, pedologia, uso e cobertura solo e clima (RUELA, 2015).

As ações promotoras de impactos ambientais estão diretamente associadas ao balanço morfogênese/pedogênese (TRICART, 1977). O processo de morfogênese, ocorrem não apenas de forma natural, como também por ações antrópicas. Sendo assim, as intervenções humanas podem acarretar um desequilíbrio do ciclo natural dos aspectos fisiográficos, contribuindo para a aceleração dos processos erosivos que alteram todo o meio ambiente (ROSS, 1994).

O Complexo Guanambi detém a maior parcela em área da bacia e foi classificado como um meio Estável, devido a seu grau de vulnerabilidade apresentar um valor de 1,2, seguido do Complexo Santa Isabel $(1,3)$ e Rochas Máficas e Ultamarficas $(1,3)$ que também foram classificados dentro dessa faixa. Classificou-se como Moderadamente Estável a Formação Sítio Novo $(1,6)$, Supergrupo Espinhaço $(1,7)$ e a Formação Canatiba $(1,7)$, posteriormente foram classificadas como Medianamente Estável/Vulnerável a Formação Palmas de Monte Alto $(2,0)$ e o Greenstone Belt Brumado (2,2). Por fim, a unidade geológica pertencente a Cobertura Detrito-Laterítica Paleogênica $(2,6)$ foi classificada como Moderadamente Vulnerável (Quadro 1; Figura 5).

A Geologia compreende as informações relativas aos ciclos evolutivos geológicos presentes na unidade de paisagem, bem como, ainda detém no que se diz respeito a estrutura do solo os dados voltados ao grau de coesão das partículas sólidas que o integram (CREPANI, et al., 2001). Mediante este fato, tem-se que os graus de coesão dessas partículas irão influenciar diretamente no balanço Morfogênese/Pedogênese, em que, a pouca coesão desses, irá proporcionar a sedimentação das partículas por desprendimentos, prevalecendo neste caso os processos de Morfogênese, no entanto caso exista coesão, prevalecerá os processos de Pedogênese (TRICART, 1977). Nesse sentido, concluiu-se que houve a prevalência dos processos de pedogênese (formadores de solo), uma vez que o meio Estável possui maior predominância sobre microbacia do Rio Carnaíba de Dentro (BA), para o aspecto fisiográfico geológico.

Quadro 1 - Vulnerabilidade das unidades geológicas presentes na área de estudo.

\begin{tabular}{|c|c|c|c|c|c|}
\hline & $\begin{array}{c}\text { UNIDADE } \\
\text { GEOLÓGICA }\end{array}$ & $\begin{array}{l}\text { FORMAÇÃO } \\
\text { PRINCIPAL }\end{array}$ & ÁREA $\left(\mathbf{k m}^{2}\right)$ & $\begin{array}{l}\text { \% DA } \\
\text { ÁREA }\end{array}$ & $\begin{array}{c}\text { GRAU DE } \\
\text { VULNERABILIDADE }\end{array}$ \\
\hline 1 & $\begin{array}{l}\text { Complexo } \\
\text { Guanambi }\end{array}$ & $\begin{array}{l}\text { Granito; } \\
\text { Granodiorito } \\
\text { e Sientido }\end{array}$ & $2.037,262$ & 79,07 & 1,2 \\
\hline 2 & $\begin{array}{c}\text { Complexo Santa } \\
\text { Isabel }\end{array}$ & $\begin{array}{c}\text { Gnasse; } \\
\text { Granodiorito; } \\
\text { Sienito e Migmatito }\end{array}$ & 299,650 & 11,63 & 1,3 \\
\hline & $\begin{array}{l}\text { UNIDADE } \\
\text { GEOLÓGICA }\end{array}$ & $\begin{array}{l}\text { FORMAÇÃO } \\
\text { PRINCIPAL }\end{array}$ & ÁREA $\left(\mathbf{k m}^{2}\right)$ & $\begin{array}{l}\text { \% DA } \\
\text { ÁREA }\end{array}$ & $\begin{array}{c}\text { GRAU DE } \\
\text { VULNERABILIDADE }\end{array}$ \\
\hline
\end{tabular}


Vulnerabilidade natural à perda de solo da microbacia hidrográfica do rio Carnaíba de Dentro, Semiárido Baiano

Jardel Gybson Soares Costa; Mateus R. Caetano; Carlos Magno Santos Clemente

\begin{tabular}{|c|c|c|c|c|c|}
\hline 3 & $\begin{array}{c}\text { Greenstone Belt } \\
\text { Brumado }\end{array}$ & $\begin{array}{l}\text { Conglomerado; } \\
\text { Filito e Xisto }\end{array}$ & 515 & $\mathbf{0 , 0 2}$ & 2,2 \\
\hline 4 & $\begin{array}{c}\text { Formação Sítio } \\
\text { Novo }\end{array}$ & Filito e Quartizito & 20,345 & $\mathbf{0 , 7 9}$ & 1,6 \\
\hline 5 & $\begin{array}{l}\text { Supergrupo } \\
\text { Espinhaço }\end{array}$ & Arenito e Quartizito & $\mathbf{8 8 , 8 9 0}$ & 3,45 & 1,7 \\
\hline 6 & $\begin{array}{c}\text { Formação } \\
\text { Canatiba }\end{array}$ & $\begin{array}{c}\text { Arenito; Filito; } \\
\text { Quartizo Diorito e } \\
\text { Quartizito }\end{array}$ & 30,661 & 1,19 & 1,7 \\
\hline 7 & $\begin{array}{c}\text { Cobertura Detrito- } \\
\text { Laterítica } \\
\text { Paleogênica }\end{array}$ & $\begin{array}{c}\text { Arenito; } \\
\text { Inconsolidados } \\
\text { e conglomerado }\end{array}$ & 64,929 & 2,52 & 2,6 \\
\hline 8 & $\begin{array}{l}\text { Formação Palmas } \\
\text { de Monte Alto }\end{array}$ & $\begin{array}{c}\text { Arenito; Quartizito e } \\
\text { Siltito }\end{array}$ & 23,189 & $\mathbf{0 , 9 0}$ & 2 \\
\hline 9 & $\begin{array}{c}\text { Rochas Máficas e } \\
\text { Ultramáficas }\end{array}$ & $\begin{array}{c}\text { Diorito; Gabro e } \\
\text { Granulito }\end{array}$ & 4,638 & 0,18 & 1,3 \\
\hline
\end{tabular}

Fonte: CPRM, 2010. Org.: Autores, 2020

Figura 5 - Vulnerabilidade a perda de solo para variável de Geologia da Microbacia do Rio Carnaíba de Dentro (BA)

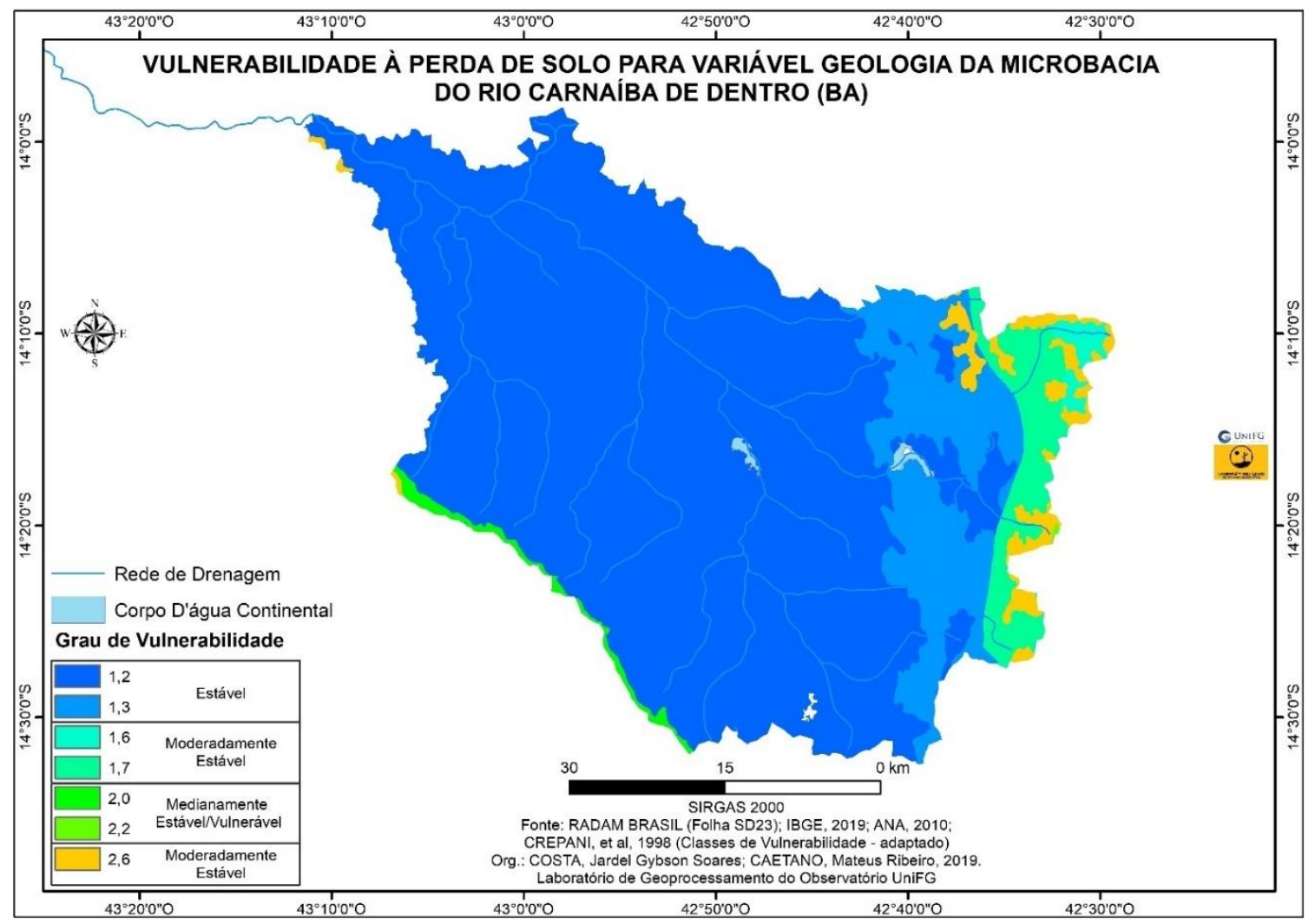

Fonte: RADAM BRASIL (Folha SD23); IBGE, 2019; ANA, 2010; CREPANI et al, 1998 Org.: COSTA, Jardel Gybson Soares, CAETANO, Mateus Ribeiro, 2019.

A declividade atribuída a bacia, evidenciou 5 (cinco) classes de vulnerabilidade associadas aos 5 (cinco) intervalos percentuais apresentados por sua caracterização, o primeiro intervalo $(<2)$, ao qual abrange $53,58 \%$ da área total da bacia, foi classificado como um meio Estável (1,0). Nesse sentido, o segundo intervalo (2-6), presente em 31,92\% da área total, foi classificado como um meio Moderadamente Estável (1,5), posteriormente o terceiro intervalo 
Vulnerabilidade natural à perda de solo da microbacia hidrográfica do rio Carnaíba de Dentro, Semiárido Baiano

Jardel Gybson Soares Costa; Mateus R. Caetano; Carlos Magno Santos Clemente

(6-20), ao qual ocupa $13,86 \%$ da área total, foi classificado como um meio Medianamente Estável/Vulnerável (2,0) (Figura 6).

Em seguida o quarto intervalo (20-50), representou 0,63\% da área total, foi classificado como um meio Moderadamente Vulnerável $(2,5)$ e, por fim o quinto intervalo (>50), que contemplou $0,01 \%$ da área total, foi classificado como um meio Vulnerável $(3,0)$. Nesse contexto, ao considerar a análise dos resultados acerca da área total, para a variável declividade, pode-se afirmar que houve a prevalência dos processos de pedogênese (formadores de solo), uma vez que o meio Estável possui maior predominância sobre a bacia, ao qual contempla $53,58 \%$ da área total (Figura 6-A).

A amplitude total da microbacia do Rio Carnaíba de Dentro (BA), possui uma variação de 446 a 1322m, considerou-se para classificação da vulnerabilidade a cota mais baixa (446m) como 0 , a qual indicou a variação total de 0 a $876 \mathrm{~m}$. Nessa perspectiva, foram evidenciadas 5 (cinco) classes de vulnerabilidade associadas aos 5 (cinco) intervalos altimétricos. a primeira amplitude altimétrica $(<20 \mathrm{~m})$, a qual abrange $0,67 \%$ da área total da bacia, foi classificada como um meio Estável $(1,0)$. Nesse seguimento, a segunda amplitude $(58-67,5 \mathrm{~m})$, que contempla $22,07 \%$ da área total, foi classificada como um meio Moderadamente Estável $(1,5)$.

Posteriormente a terceira amplitude altimétrica (103,5-113m), a qual ocupa 24,96\% da área total, foi classificada como um meio Medianamente Estável/Vulnerável (2,0), a quarta amplitude altimétrica (151-160,5m), representou 15,11\% da área total, foi classificada como um meio Moderadamente Vulnerável $(2,5)$ e, por fim o quinto intervalo (>200m), que contemplou $37,19 \%$ da área total, foi classificada como um meio Vulnerável $(3,0)$. Ao considerar a análise dos resultados em função da área total da bacia, para a variável altimétrica, percebe-se que houve a prevalência dos processos de morfogênese (processos erosivos, modificadores das formas de relevo), uma vez que o meio Vulnerável possui maior abrangência sobre a bacia, ao qual representou 37,19\% da área total. (Figura 6-B).

Foram identificados como um meio Estável, duas regiões, a primeira $(1,0)$ compreende $0,60 \%$ da área da bacia e, a segunda $(1,2) 18,59 \%$ da área, ao qual totalizou 19,19\% em relação a área total, estas estão estabelecidas a noroeste nas cotas mais baixas da bacia. No mais, classificou-se como um meio Moderadamente Estável, duas regiões, a primeira $(1,5)$ abrange $21,91 \%$ da área da bacia e, a segunda $(1,7)$ 14,62\% da área, ao qual totalizou 36,53\% da área total, estas estão estabelecidas na região central se alastrando para o noroeste (Figura 7).

O meio classificado como Medianamente Estável/Vulnerável, apresentou duas regiões, a primeira (2,0) contempla $13,65 \%$ da área da bacia e, a segunda $(2,2) 17,68 \%$ da área, ao qual totalizou $31,33 \%$ da área total, estas estão estabelecidas nas regiões sudoeste, sudeste e 
Vulnerabilidade natural à perda de solo da microbacia hidrográfica do rio Carnaíba de Dentro, Semiárido Baiano

Jardel Gybson Soares Costa; Mateus R. Caetano; Carlos Magno Santos Clemente

nordeste. Em seguida, classificou-se como Moderadamente Vulnerável, uma região $(2,5)$ que ocupa $12,33 \%$ da área total da bacia, esta é predominante nas regiões centrais, sudoeste, sudeste e nordeste (Figura 7).

Por fim, foram reconhecidas como um meio vulnerável, duas regiões, a primeira $(2,7)$ ocupa $0,62 \%$ da área da bacia e, a segunda $(3,0)$ apenas $0,01 \%$ da área, ao qual totalizou $0,63 \%$ em relação a área total, estas são predominantes nas cotas mais altas da bacia (Figura 7).

A Geomorfologia compreende as informações relativas a Morfometria, ou seja, deve-se levar em conta as informações que caracterizam as formas de relevo, tais como, a declividade e a amplitude do relevo. Com isso, torna-se possível identificar o grau de energia potencial que atua sobre a unidade por meio de precipitações pluviométricas (CREPANI, et al., 2001).

Desse entendimento, tem-se o escoamento superficial diante de das amplitudes de relevos, irão transformação sua energia potencial em cinética, assim, culminado com uma declividade acentuada, irão contribuir significativamente para os processos erosivos, prevalecendo a Morfogênese. Contudo em casos onde a Morfometria não apresente valores expressivos que contribuam para grandes aumentos da energia cinética do escoamento superficial, prevalecerá os processos Pedogênese (TRICART, 1977).

Dado exposto observa-se que a microbacia do Rio Carnaíba de Dentro (BA), apresenta baixos índices de inclinação do terreno, sendo que na maior parte da sua área o relevo é plano $(<2)$, apresentando em sua maioria altitudes medianas a baixas. Para tanto, em função da análise dos resultados acerca da área total, para a variável relativa à geomorfologia, indica a prevalência dos processos de pedogênese (formadores de solo), uma vez que o meio Moderadamente Estável possui maior predominância sobre a bacia, o qual contempla 36,53\% da área total.

Figura 6 - Vulnerabilidade a perda de solo para as variáveis Declividade e Altimetria da Microbacia do Rio Carnaíba de Dentro (BA) 
Vulnerabilidade natural à perda de solo da microbacia hidrográfica do rio Carnaíba de Dentro, Semiárido Baiano

Jardel Gybson Soares Costa; Mateus R. Caetano; Carlos Magno Santos Clemente

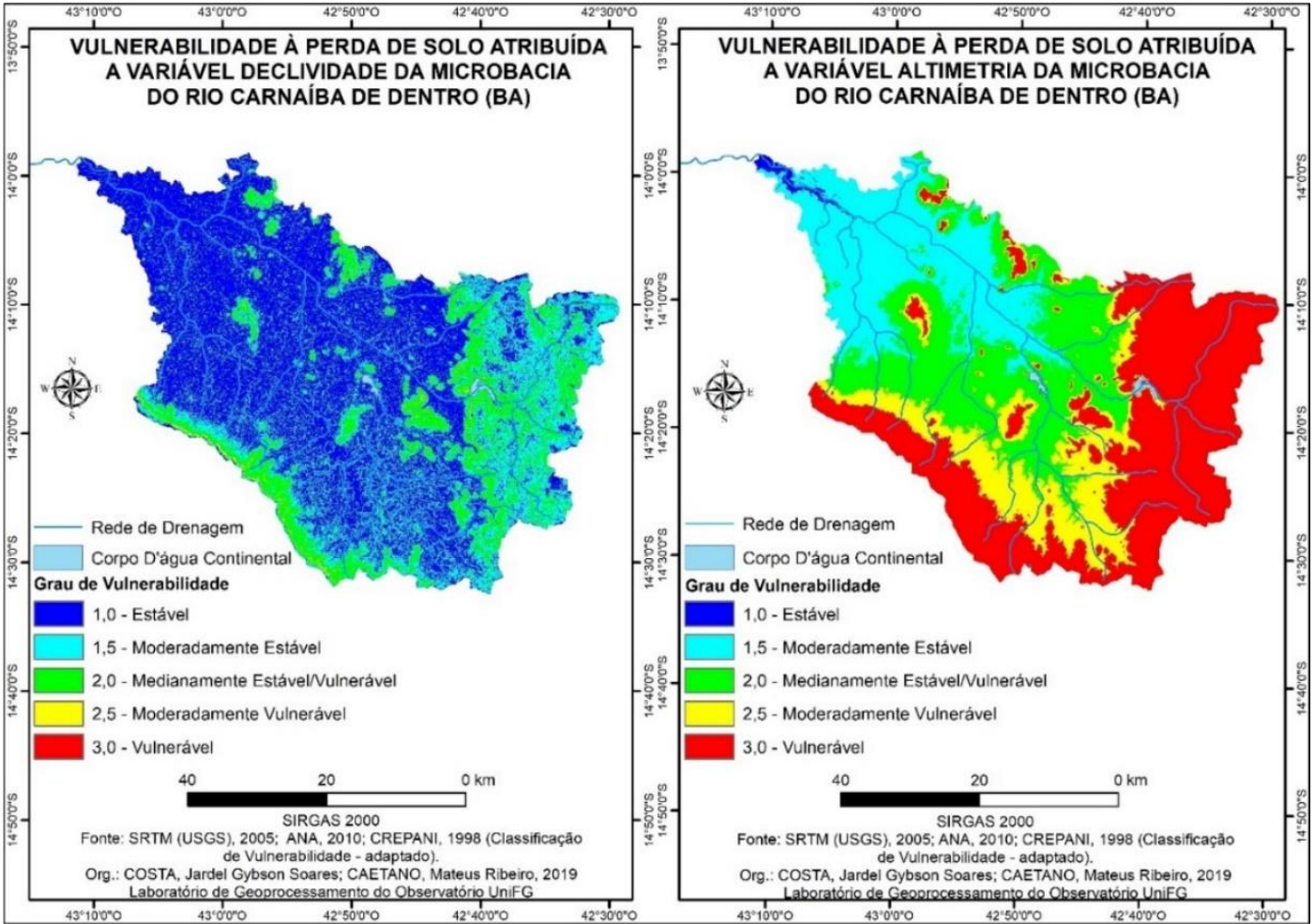

Fonte: SRTM (USGS), 2005; ANA, 2010; CREPANI et al, 1998

Figura 7 - Vulnerabilidade à perda de solo para variável de Geomorfologia da Microbacia do Rio Carnaíba de Dentro (BA)

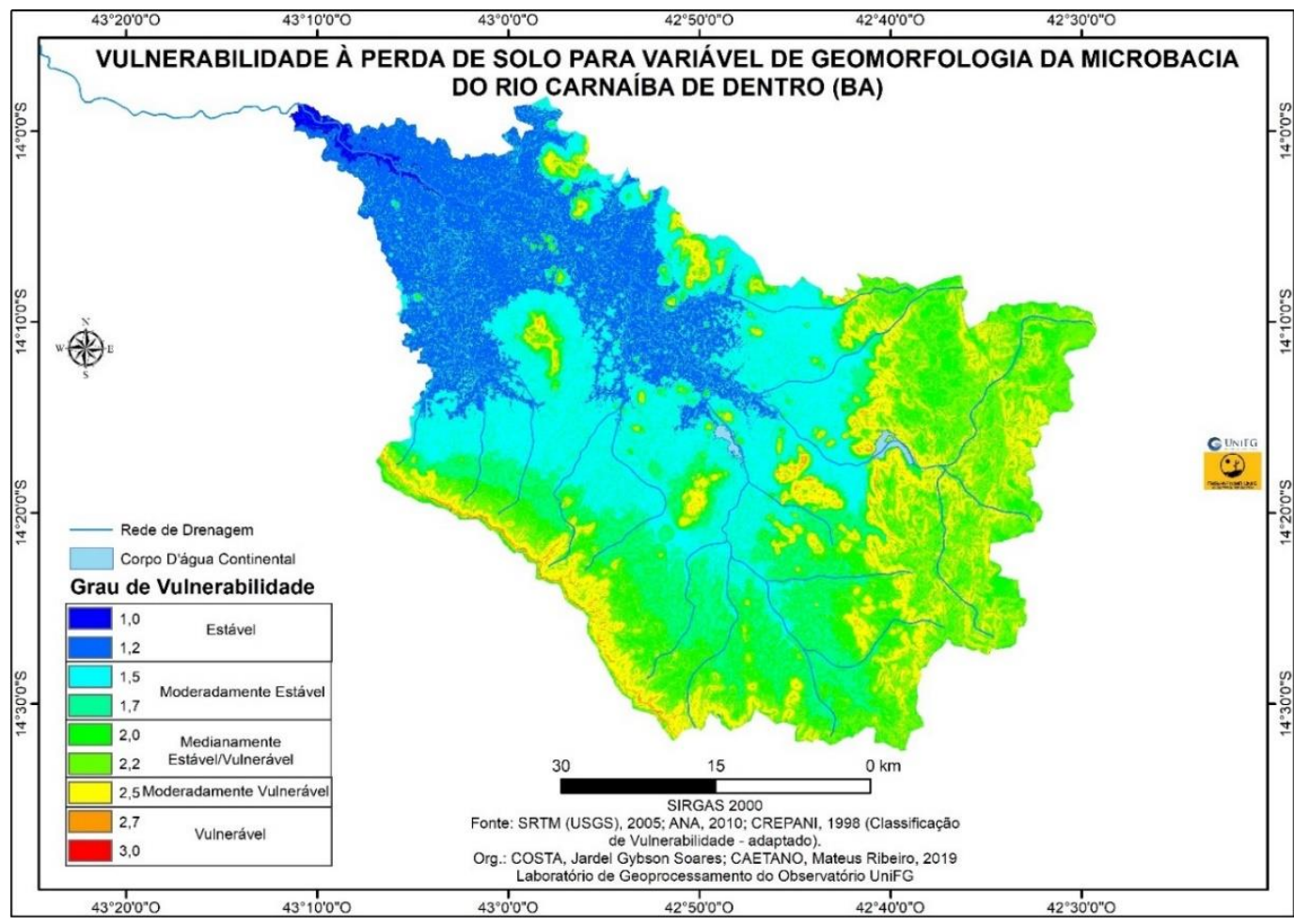

Fonte: SRTM (USGS), 2005; ANA, 2010; CREPANI et al, 1998

Org.: COSTA, Jardel Gybson Soares, CAETANO, Mateus Ribeiro, 2019

Foram classificados como um meio Estável o Latossolo Amarelo Distrófico $(1,0)$ e o Latossolo Vermelho-Amarelo Eutrófico $(1,0)$, aos quais juntos apresentaram a uma área 
Vulnerabilidade natural à perda de solo da microbacia hidrográfica do rio Carnaíba de Dentro, Semiárido Baiano

Jardel Gybson Soares Costa; Mateus R. Caetano; Carlos Magno Santos Clemente

correspondente a $21.19 \%$ da bacia. Nesse contexto, apresentaram-se como um meio Medianamente Estável/Vulnerável os Argissolo Vermelho-Amarelo Distrófico (2,0), Argissolo Vermelho Eutrófico $(2,0)$ e o Planossolo Háplico Eutrófico $(2,0)$ aos quais juntos contemplam uma área correspondente a 56,02\% da bacia (Figura 8).

Nessa perspectiva, ainda, foram classificados o Cambissolo Háplico Eutrófico $(2,5)$ como um meio Moderadamente Vulnerável, apresentando a uma área total correspondente a 14,27\% da bacia e, o Neossolo Litólico Distrófico $(3,0)$ como um meio Vulnerável, evidenciando uma área correspondente a 8,29\% da bacia (Figura 8).

A Pedologia se caracteriza por estudar a maturidade dos solos com base no conceito de Ecodinâmica. Logo, o balanço Morfogênese/Pedogênese está diretamente relacionado a idade do solo, onde, em solos jovens, com pouco desenvolvimento prevalecem os processos de Morfogênese, no entanto, em solos maduros, lixiviados e que se encontram em locais estáveis, prevalecerá sobre estes os processos de Pedogênese (TRICART, 1977).

Para tanto, ao levar em consideração a análise dos resultados sobre área total, para a variável temática referente a pedologia, conclui-se que houve um equilíbrio entre a pedogênese/morfogênese, uma vez que o meio Medianamente Estável/Vulnerável possui maior incidência sobre microbacia do Rio Carnaíba de Dentro (BA), para o aspecto fisiográfico correspondente a temática pedológica.

Figura 8 - Vulnerabilidade a perda de solo para variável de Pedologia da Microbacia do Rio Carnaíba de Dentro (BA) 
Vulnerabilidade natural à perda de solo da microbacia hidrográfica do rio Carnaíba de Dentro, Semiárido Baiano

Jardel Gybson Soares Costa; Mateus R. Caetano; Carlos Magno Santos Clemente

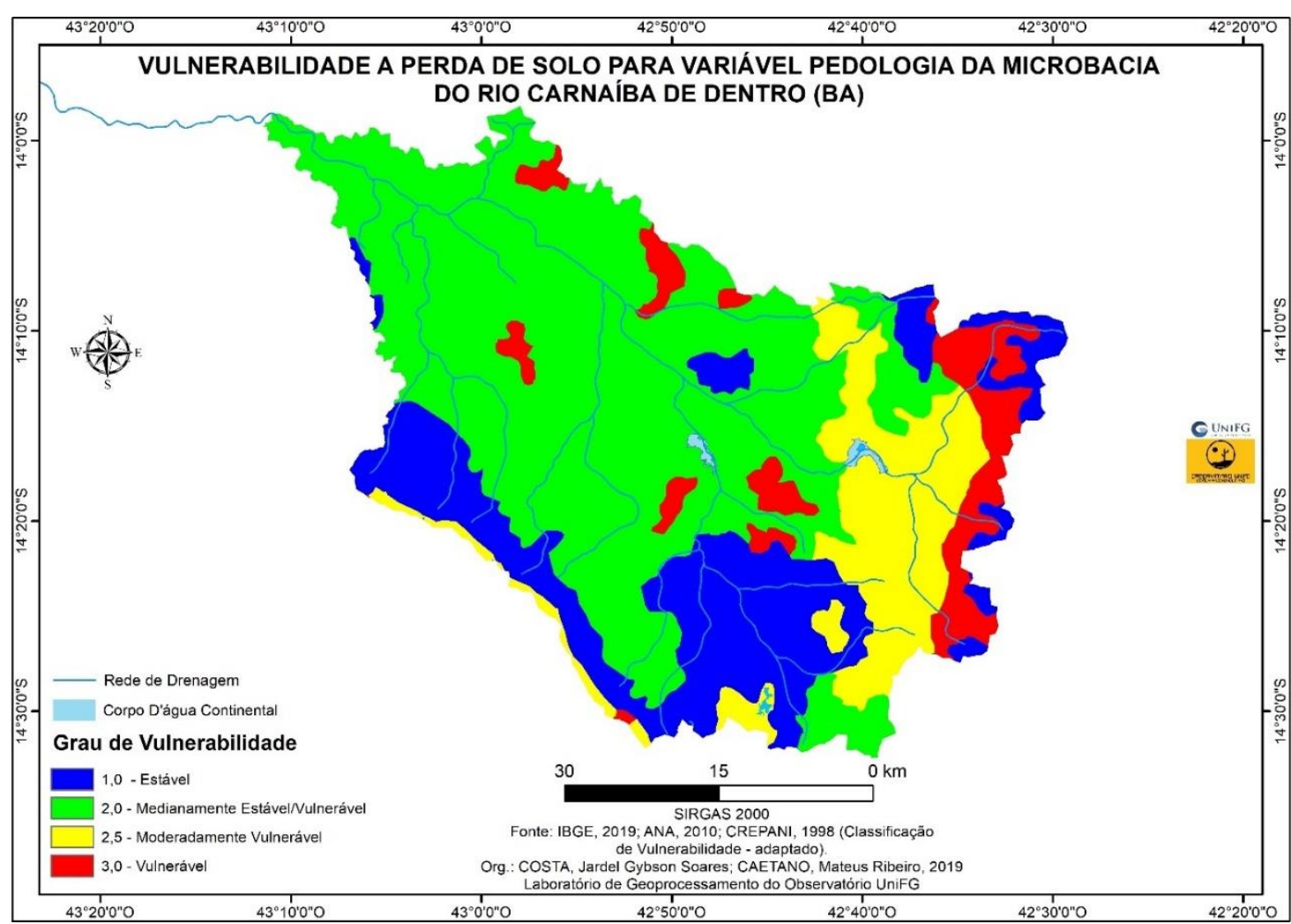

Fonte: IBGE, 2019; EMBRAPA, 1973; ANA, 2010; CREPANI et al, 1998

Org.: Autores, 2019

A partir da caracterização do uso e cobertura do solo presente na microbacia do Rio Carnaíba de Dentro (BA), foi possível identificar a vulnerabilidade natural à perda de solo vinculada a este tema (Figura 9). Foram identificados 5 (cinco) graus de vulnerabilidade, associados a 5 (cinco) classes. Para tanto, classificou-se como um meio Estável $(1,0)$, uma região que compreende $1,26 \%$ da área da bacia, em seguida foi classificado como um meio Moderadamente Estável $(1,5)$, o equivalente a 46,97\% da área da bacia. Nesse contexto, o meio identificado pela classe Medianamente Estável/Vulnerável $(2,0)$, apresentou sua incidência em apenas $0,01 \%$ da área da bacia (Figura 9).

Em seguida o meio classificado como Moderadamente Vulnerável (2,5), também demonstrou uma abrangência pequena sobre a bacia, contemplando apenas $0,05 \%$ da sua área. Contudo, a maior parcela de área da bacia foi estabelecida pelo meio pertencente a classe Vulnerável (3,0), a qual apresentou sua incidência em 51,72\% da área total (Figura9).

Figura 9 - Vulnerabilidade a perda de solo para variável de Uso e Cobertura do Solo da Microbacia do Rio Carnaíba de Dentro (BA) 
Vulnerabilidade natural à perda de solo da microbacia hidrográfica do rio Carnaíba de Dentro, Semiárido Baiano

Jardel Gybson Soares Costa; Mateus R. Caetano; Carlos Magno Santos Clemente

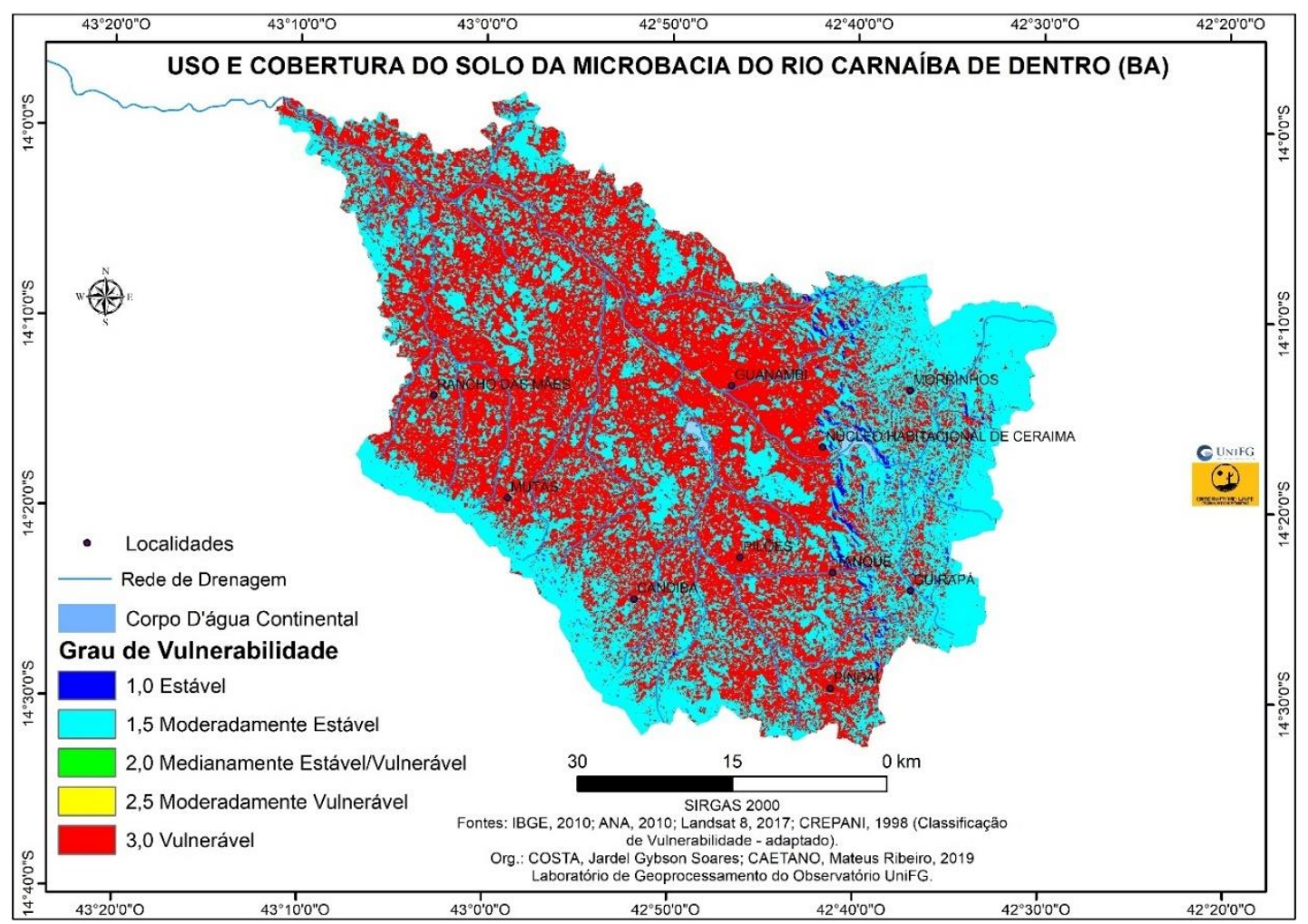

Fonte: IBGE, 2019; ANA, 2010; Landsat 8, 2017; CREPANI et al, 1998

Org.: Autores, 2019

A cobertura vegetal se qualifica como um agente de proteção dos solos (CREPANI, et al., 2001). Desse modo, em áreas cuja vegetações são menos densas prevalecem os processos de morfogênese, devido à falta de cobertura vegetal que protege os solos das adversidades climáticas, no entanto caso a unidade possua uma vegetação densa, prevalecerá os processos de Pedogênese. Vale ainda ressaltar, que o uso do solo se relaciona diretamente aos polígonos de intervenção antrópica, que são entendidos como os agentes modificadores da unidade de paisagem natural, onde sua ocupação pode abranger mais de uma unidade de paisagem natural, a depender de sua extensão (TRICART, 1977).

Em função disso, ao levar em consideração a análise dos resultados sobre área total, para a variável temática referente ao uso e cobertura do solo, conclui-se que houve a prevalência dos processos de morfogênese (processos erosivos, modificadores das formas de relevo), uma vez que o meio vulnerável possui maior incidência sobre microbacia do Rio Carnaíba de Dentro (BA), para o aspecto fisiográfico correspondente a temática uso e cobertura do solo.

A partir dessa análise observou-se a existência de 2 (dois) graus de vulnerabilidade, associados a 2 (duas) classes (Estável e Moderadamente Estável). Diante do exposto, identificou-se que o grau associado ao meio Estável $(1,3)$, se estabelece sobre a região mais ao sul da bacia que contempla apenas $0,8 \%$ da área da bacia. Os 99,2\% restantes da área da bacia foram classificados como um meio Moderadamente Estável $(1,4)$. 
Vulnerabilidade natural à perda de solo da microbacia hidrográfica do rio Carnaíba de Dentro, Semiárido Baiano

Jardel Gybson Soares Costa; Mateus R. Caetano; Carlos Magno Santos Clemente

As questões climáticas ligadas aos índices pluviométricos, contribuem de forma significativa para quantificar os graus de risco atuante sobre a unidade de paisagem (CREPANI, et al., 2001). Sendo assim, em situações onde predomine altos índice pluviométrico, concentrado em um curto período, desencadeia-se um escoamento superficial de grandes proporções, assim, prevalece sobre essa situação os processos de Morfogênese, por outro lado, caso os índices pluviométricos sejam baixos prevalecera a Pedogênese (TRICART, 1977).

Logo, ao levar em consideração a análise dos resultados acerca da área total, para a variável temática referente ao clima, constata-se que houve a prevalência dos processos de pedogênese (formadores de solo), uma vez que o meio Estável possui grande predominância, contemplando $99,5 \%$ da área total da microbacia do Rio Carnaíba de Dentro (BA). Tais considerações estão relacionadas ao aspecto fisiográfico correspondente as variáveis climáticas.

\section{Vulnerabilidade natural à perda de solo da microbacia hidrográfica do rio carnaíba de} dentro (ba)

Conforme Tricart (1977) o grau de vulnerabilidade de todo semiárido o classifica como um meio instável, no qual, prevalece o predomínio da morfogênese sobre a pedogênese. Contudo, a região da microbacia hidrográfica do Rio Carnaíba de Dentro (BA), situada no semiárido brasileiro, é formada por características peculiares da geologia, geomorfologia, pedologia, uso e cobertura do solo e clima, que constituem um mosaico de paisagem com diferentes graus de vulnerabilidade aos processos erosivos.

Nessa perspectiva, o fato de que microbacia hidrográfica do Rio Carnaíba de Dentro (BA) se estabelece sobre uma região semiárida, enfatizou a importância de um estudo aprofundado desta, no sentido de que tal região possui grandes chances de tornar-se vulnerável aos processos de morfogênese. Destarte, as regiões semiáridas detêm aspectos intrínsecos no que diz respeito à sua alta susceptibilidade à processos de perda de solo, provocados principalmente pelas erosões pluviais que estão em função dos altos índices pluviométricos concentrados em um curto espaço de tempo, o tipo de cobertura do solo e suas peculiaridades em termos climáticos (BERTONI; LOMBARDI NETO, 1993).

As peculiaridades climáticas presentes no semiárido conferem a suas bacias hidrográficas altas taxas de solo erodido durante épocas em que as precipitações médias estão entre 300mm e 500mm (WALLING; WEBB, 1996). No entanto, como já foi visto, o resultado acerca da variável climática atuante sobre a microbacia do Rio Carnaíba de Dentro (BA), 
Vulnerabilidade natural à perda de solo da microbacia hidrográfica do rio Carnaíba de Dentro, Semiárido Baiano

Jardel Gybson Soares Costa; Mateus R. Caetano; Carlos Magno Santos Clemente

demonstrou-se favorável a prevalência da pedogênese, em função dos baixos indicies de precipitação evidenciados.

Ainda nessa perspectiva, de acordo com Cardoso et al. (2006), tanto a cobertura de solo pela ocupação vegetal quanto a declividade do terreno, exercem forte influência na tomada de decisões acerca do manejo de uma bacia hidrográfica. Nesse sentido, tais fatores são influenciados principalmente pela precipitação, em decorrência do fluxo de água no solo e escoamento superficial (CARDOSO et al., 2006). Logo, a ausência de cobertura do solo, grande intensidade pluviométrica e um alto grau de declividade, contribuem para o aumento da velocidade de escoamento e menor infiltração de água, resultando na degradação do solo por meio dos processos de morfogênese (TONELLO et al., 2006).

Daí com relação à declividade e amplitude altimétrica observadas na microbacia do Rio Carnaíba de Dentro (BA), tem-se que estas apresentaram um terreno plano em quase toda a sua extensão de área sem muitas alterações bruscas de altitude, contribuindo desse modo para menor escoamento superficial e maior infiltração de água no solo, assim, desembocando em uma geomorfologia a qual prevaleceu os processos de pedogênese.

Uma bacia hidrográfica se apresenta como uma categoria de suma importância para análise ambiental, ao proporcionar uma investigação holística de vários elementos, recursos e relações nela presente, especialmente, quando o foco das pesquisas constitui em desenvolverse de forma sistêmica e integrada (BOTELHO; SILVA, 2004). Nesse cenário, temos que uma bacia hidrográfica é formada pela interação dinâmica e complexa entre seus componentes, tais quais ligados aos aspectos geológicos, geomorfológicos, pedológicos, hidrológicos, antropológico e climáticos que trabalham de forma conjunta (GRIGORIEV, 1968).

Identificou-se o meio Estável associado a 2 (dois) graus, o primeiro $(1,2)$ compreende apenas $0,0004 \%$ da área da bacia, o segundo $(1,3) 0,5242 \%$ da área, estes referentes as localidades que apresentam as maiores porções de corpos d'água, solos bem lixiviados, terreno plano e com boa cobertura do solo. Para tanto, o meio Estável evidenciou sua abrangência em 0,5246\% em relação a área total, prevalecendo, assim, nestes locais os processos de pedogêndese (Figura 10).

O meio Moderadamente Estável, foi identificado por meio da associação de 4 (quatro) graus, o primeiro $(1,4)$ foi observado em $0,7977 \%$ da área da bacia, o segundo $(1,5) \mathrm{em} 7,9171 \%$ da área, em seguida o terceiro $(1,6)$ se mostrou presente em $7,1453 \%$ da área e, por fim o quarto $(1,7)$ contemplou $5,4764 \%$ da área. Esses referentes a localidades cuja distribuição é homogênea pela região noroeste, que detém as cotas mais baixas da bacia, relativa cobertura do solo, baixos índices pluviométricos, pouca declividade e geologia desfavorável aos processos 
Vulnerabilidade natural à perda de solo da microbacia hidrográfica do rio Carnaíba de Dentro, Semiárido Baiano

Jardel Gybson Soares Costa; Mateus R. Caetano; Carlos Magno Santos Clemente

de denudação das rochas. Para tanto, o meio Moderadamente Estável evidenciou sua abrangência em $21,3365 \%$ em relação a área total, prevalecendo, nestas localidades os processos de pedogêndese (Figura 10).

Observou-se o meio Medianamente Estável/Vulnerável, associado a 5 (cinco) graus, o primeiro $(1,8)$ evidenciou 22,7797\% da área da bacia, o segundo $(1,9)$ em 18,0802\% da área, em seguida o terceiro $(2,0)$ se mostrou presente em 9,3046\% da área, posteriormente o quarto $(2,1)$ em $13,8252 \%$ da área e, por fim o quinto $(2,2)$ que contemplou $7,0585 \%$ da área(Figura $10)$.

Esses estão situados de forma distribuída e homogênea em todo território da microbacia, tais locais favorecem o equilíbrio entre os processos formadores e degradadores de solo, em função das característica fisiográficas que induzem a estabilidade. Como a cobertura parcial do solo, que culminada a declividades medianas e, a presença de solos com graduação moderada, favorecem a ocorrência desse cenário. Para tanto, o meio Medianamente Estável/Vulnerável evidenciou sua abrangência em 71,0482\% em relação a área total, prevalecendo, nestas localidades um equilíbrio entre os processos de pedogênese/morfogênese (Figura 10).

O meio Moderadamente Vulnerável, foi associado a 4 (quatro) graus, o primeiro $(2,3)$ foi observado em 2,6487\% da área da bacia, o segundo $(2,4)$ em 3,9684\% da área, em seguida o terceiro $(2,5)$ se mostrou presente em $0,4674 \%$ da área e, por fim o quarto $(2,6)$ contemplou apenas $0,0153 \%$ da área. Esses referentes aos locais cuja distribuição é concentra nas regiões que apresentaram as maiores declividades e cotas altimétricas, como o perímetro da Serra do Espinhaço, a depressão da Serra de Monte Alto e, eventuais porções de terra mais elevadas. Para tanto, o meio Moderadamente Vulnerável evidenciou sua abrangência em apenas 7,0998\% em relação a área total, prevalecendo, nestas localidades os processos de morfogênese (Figura $10)$.

Figura 10 - Vulnerabilidade à perda de solo da Microbacia do Rio Carnaíba de Dentro (BA) 
Vulnerabilidade natural à perda de solo da microbacia hidrográfica do rio Carnaíba de Dentro, Semiárido Baiano

Jardel Gybson Soares Costa; Mateus R. Caetano; Carlos Magno Santos Clemente

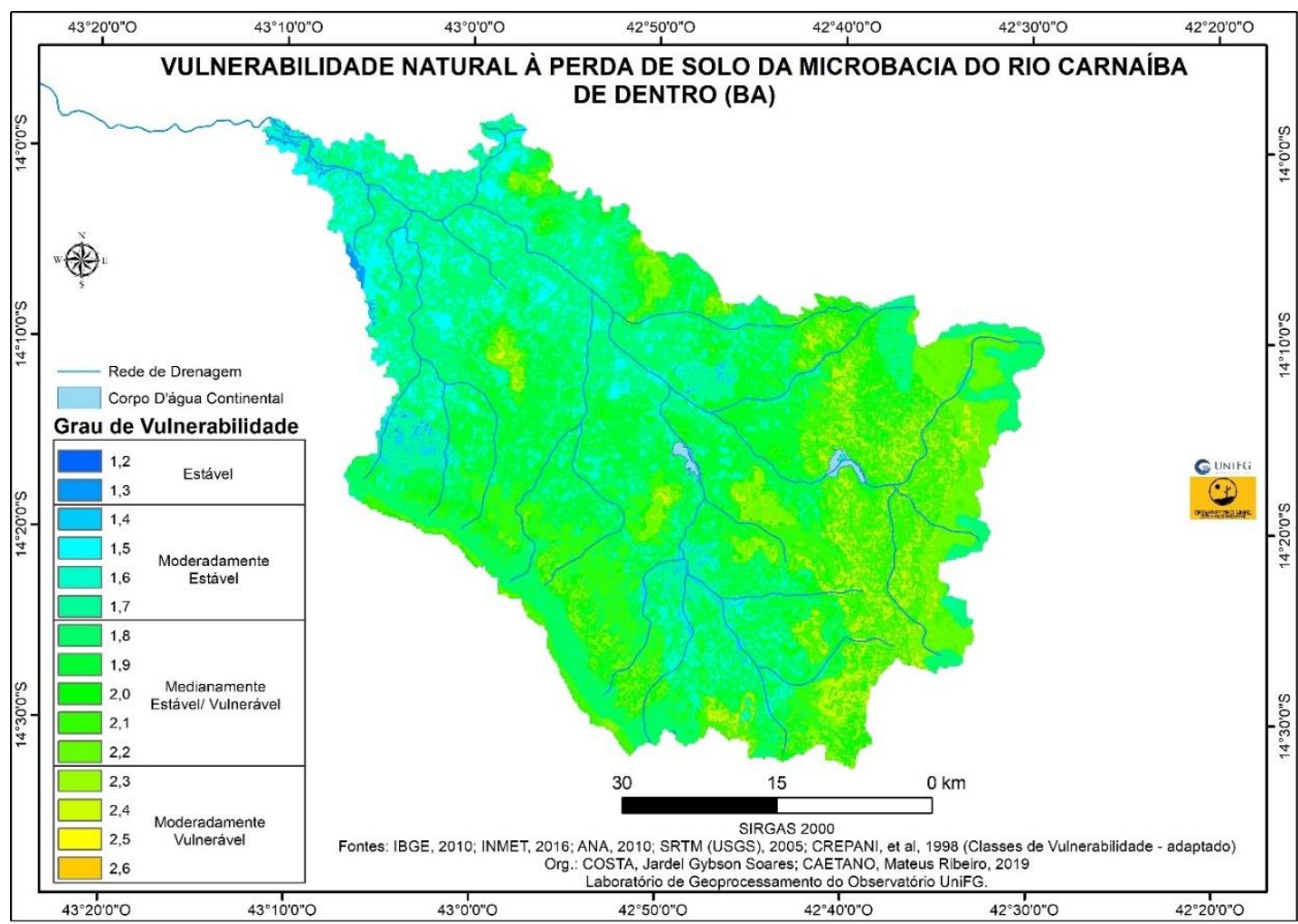

Fonte: IBGE, 2019; INMET, 2016; ANA, 2010; SRTM (USGS), 2005; CREPANI et al, 1998 (Classes de Vulnerabilidade - adaptado)

Org.: Autores, 2019

Em função disso, ao levar em consideração a análise dos resultados sobre área total, conclui-se que houve um equilíbrio entre a pedogênese/morfogênese, uma vez que o meio Medianamente Estável/Vulnerável possui maior incidência sobre microbacia do Rio Carnaíba de Dentro, contrariando, dessa forma, a hipótese da prevalência dos processos de morfogênse, aos quais atuam majoritariamente sobre todo semiárido brasileiro.

Apesar desse cenário a microbacia tem sido intensamente degradada nos seus anos de ocupação. Em áreas de agentes formadores de solos cujo ocorrem a prevalência dos processos de pedogênesse, as ações antrópicas estão gradualmente mudando as características naturais dos meios estáveis. Tais eventos estão em função do crescimento da mancha urbana que promove a impermeabilização do solo, bem como por aspectos relacionados ou setor agropecuários, que degradam o solo por meios abrasivos. Nesse contexto, é de fundamental importância atentar-se aos avanços dos polígonos de intervenção antrópica, por meio de estudos do espaço geográfico, evidenciando a interação dinâmica entre as variáveis ali existentes.

Logo pode-se afirmar, que uma bacia hidrográfica possui, mecanismos que possibilitam realizar uma análise integrada do meio ambiente, visto que permite ações diretas e indiretas do homem no que tange a construção de um agrupamento de relações naturais e antrópicas heterogêneas, pela reinterpretação de seus elementos (SANTOS, 2011). Dessas acepções, podemos ressaltar que ao articular-se de forma conjunta as categorias homem e natureza em um 
Vulnerabilidade natural à perda de solo da microbacia hidrográfica do rio Carnaíba de Dentro, Semiárido Baiano

Jardel Gybson Soares Costa; Mateus R. Caetano; Carlos Magno Santos Clemente

contexto de análise ambiental integrada, obtém-se sob a visão sistêmica, as afinidades entre os componentes que integra o cenário de uma bacia hidrográfica e permite o estudo de seus resultados espaciais (SANTOS, 2011).

Daí a necessidade de uma gestão das bacias hidrográficas à luz do planejamento ambiental (SCHIAVETTI; CAMARGO, 2002). Nesse contexto, possibilita-se que seja averiguado o grau de impacto ambiental, a fim de implementar por meio de ações a intervenção, recuperação e preservação das áreas suscetíveis a fragilidade natural (SCHIAVETTI; CAMARGO, 2002). Em função disso, entra em cena os mapas de vulnerabilidade natural à perda de solo como uma ferramenta eficaz de gestão do espaço territorial, que pode servir de subsídio por exemplo ao zoneamento ambiental (SCHIAVETTI; CAMARGO, 2002).

Conforme Becker e Egler (1996), o zoneamento ambiental ou zoneamento ecológicoeconômico (ZEE) surgiu por volta dos anos 1980, como o mecanismo mais importante de gestão ambiental. Nesse sentido, o ZEE consiste em uma ferramenta de planejamento integrado que abrange desde o âmbito nacional até o municipal, onde, por meio de ações organizacionais do espaço, promove-se uma efetiva gerência dos recursos ambientais e do uso e ocupação ideal do solo (RIBEIRO, 1998).

Em virtude disso, o emprego do ZEE busca acrescer ao Governo o entendimento sobre técnicas de espacialização das políticas públicas com foco na administração do Ordenamento territorial (SANTOS; RANIERI, 2013). Entende-se em termos literários, que o ordenamento do território é a integração antrópica com o espaço natural, no qual dispõe da capacidade de coordenar as políticas econômicas, sociais, culturais e ecológicas (SANTOS; RANIERI, 2013). Desse entendimento, temos que o ZEE estuda analisar dados associados ao espaço geográfico, os quais são obtidos através do uso indispensável das geotecnologias (SANTOS; RANIERI, 2013). As Geotecnologias estão associadas ao emprego e a análise espacial de informações geográficas, bem como o compartilhamento desses dados (ROSA, 2005).

Diante do esclarecimento acerca do emprego das geotecnologias, entende-se que ela traz consigo a possibilidade de fazer uso de todo o potencial disponível no Sensoriamento Remoto e Sistemas de Informação Geográfica, proporcionando perfeitamente o desenvolvimento da aplicação da metodologia de construção de mapas de vulnerabilidade à perda de solo (AMARAL; ROSS, 2009). Coaduna-se com essas reflexões Amaral e Ross (2009), quando ressalta que um software que opera por meio de geotecnologias, quando bem manipulado, tem o potencial de proporcionar todos os parâmetros necessários para produção de mapas de vulnerabilidade à erosão. Portando, o estudo de uma bacia hidrográfica é possível pelo emprego das geotecnologias. 
Vulnerabilidade natural à perda de solo da microbacia hidrográfica do rio Carnaíba de Dentro, Semiárido Baiano

Jardel Gybson Soares Costa; Mateus R. Caetano; Carlos Magno Santos Clemente

Desse entendimento, destaca-se que a atuação humana sobre um cenário ambiental, sem informações prévias de suas características, corrobora em desfechos desastrosos no que diz respeito a preservação e manutenção dos recursos naturais deste meio (AMARAL; ROSS, 2009). Daí vem a necessidade de que se tenha um conhecimento antecipado dos componentes fisiográficos, que por meio de interação dinâmica caracterizam a unidade de paisagem natural, a fim de evitar danos irreversíveis a área de ocupação antrópica (BECKER; EGLER, 1996).

Compreender de forma holística os eventos que ocorrem em uma unidade de paisagem natural, confere ao homem o poder de mitigar a degradação ambiental dentro do polígono de intervenção antrópica, assim podendo estabelecer harmonia entre a coexistência humana e ambiental, do contrário este cenário tenderia ao desastre para ambos (CREPANI, et al., 2001). Em função disso, a construção de mapas de vulnerabilidade natural à perda de solo entrou em cena como um método eficaz de se estabelecer o grau de risco da microbacia do Rio Carnaíba de Dentro (BA), área está suscetível, servindo de ferramenta fundamental para gestão ambiental (BECKER; EGLER, 1996).

Portanto, o modo mais eficaz para lidar com os impactos causados pela morfogênese seria recorrer a medidas preventivas, ou seja, estudar o espaço geográfico a fim de localizar suas eventuais zonas de risco por meio de mapeamentos, conferindo a elas graus de vulnerabilidade à erosão, utilizando-se ferramentas de geotecnologias. Desse modo, a construção dos mapas de vulnerabilidade natural à perda de solo poderá servir de subsídio, a diversos projetos que têm como foco gerir de forma sustentável o meio ambiente, visto a falta de políticas estaduais eficazes para a preservação e conservação das bacias hidrográficas

\section{Considerações Finais}

O estudo evidenciou o equilíbrio entre os processos de morfogênese/pedogênese sobre a microbacia do Rio Carnaíba de Dentro (BA), contrariando a hipótese da prevalência dos processos de morfogênse, majoritariamente presentes em todo semiárido brasileiro. Contudo, notou-se ainda regiões susceptíveis a degradação por meio de atuações antrópicas, indicando uma diminuição das áreas classificadas como estáveis.

Nesse sentido, com o conhecimento das características acerca dos aspectos fisiográficos tornou-se possível estabelecer se estes são susceptíveis ao processo de morfogênese, um dos maiores fatores para empobrecimento dos solos e contaminação dos corpos d'água. O estudo da vulnerabilidade natural à perda de solo apresenta, ainda, dados que possam contribuir para a elaboração de projetos futuros, visando uma eficiente gestão da área analisada. Outrossim, a 
Vulnerabilidade natural à perda de solo da microbacia hidrográfica do rio Carnaíba de Dentro, Semiárido Baiano

Jardel Gybson Soares Costa; Mateus R. Caetano; Carlos Magno Santos Clemente

construção de mapas de vulnerabilidade ambiental é relevante para o subsídio de diversos estudos como Avaliação de Impactos Ambientais (AIA's), Estudos de Impacto Ambiental (EIA’s) e políticas públicas voltadas ao planejamento e ordenamento territorial.

Diante do exposto, o presente trabalho visa auxiliar no gerenciamento da microbacia em estudo, uma vez que a partir da sua caracterização é possível entender a sua dinâmica, a fim de minimizar os impactos ambientais ocasionados por fatores naturais e antrópicos. Desse modo, a partir dos dados e informações obtidas é possível fornecer suporte para um melhor direcionamento na elaboração de políticas públicas que promovam adequadamente o manejo, a ocupação e o desenvolvimento sustentável da Microbacia do Rio Carnaíba de Dentro. Vale ainda ressaltar, que a pesquisa demonstrou ser e grande importância para o desenvolvimento da área de estudo, ao identificar as causas que à deterioram, servindo, assim, de suporte para um eventual comitê da bacia hidrográfica.

\section{Referências}

AGENCIA NACIONAL DE ÁGUAS (ANA). Atlas Brasil. 2010. Disponível em: $<$ http://atlas.ana.gov.br/Atlas/forms/Download.aspx >. Acesso em: 15 Jan. 2019.

AMARAL, Rosangela do; ROSS, Jurandyr Luciano Sanches. As Unidades Ecodinâmicas na Análise da Fragilidade Ambiental do Parque Estadual do morro do Diabo e entorno, Teodoro Sampaio - SP. GEOUSP, n.26, p.59-78, 2009. Disponível em: <http://www.revistas.usp.br/geousp/article/view/74128/77771>. Acesso em: 10 Jan. 2019.

ARAÚJO, Lincoln Eloi de. et al. Bacias Hidrográficas e Impactos Ambientais. In: Qualitas Revista Eletrônica. UEPB, v. 8, n. 1. 2009. Disponível em: <http://revista.uepb.edu.br/index.php/qualitas/article/view/399/366>. Acesso em: 12 Jan. 2019.

BECKER, Bertha. K.; EGLER, Claudio. A. G. Detalhamento da metodologia para execução do zoneamento ecológico-econômico pelos estados da Amazônia Legal. Rio de Janeiro/Brasília: SAE-MMA, 1996. Disponível em: 〈http://www.egler.com.br/pdf/Metodo_ZEE.pdf>. Acesso em: 12 Jan. 2019.

BERTONI, J.; LOMBARDI NETO, F. Conservação do solo. $2^{\circ}$ ed. São Paulo: Editora Ícone, 1993. $352 \mathrm{p}$.

BOTELHO, R. G. M.; SILVA, A. S. Bacia hidrográfica e qualidade ambiental. In: VITTE, A. C.; GUERRA, A. J. T. (Orgs.). Reflexões sobre a Geografia Física no Brasil. Rio de Janeiro: Bertrand Brasil, 2004. Disponível em: 〈http://revista.fct.unesp.br/index.php/cpg/article/viewFile/3172/2656>. Acesso em: 20 Jan. 2019 
Vulnerabilidade natural à perda de solo da microbacia hidrográfica do rio Carnaíba de Dentro, Semiárido Baiano

Jardel Gybson Soares Costa; Mateus R. Caetano; Carlos Magno Santos Clemente

CARDOSO, Christiany Araujo; DIAS, Herly Carlos Teixeira; SOARES, Carlos Pedro Boechat; MARTINS, Sebastião Venâncio Caracterização morfométrica da Bacia Hidrográfica do Rio Debossan, Nova Friburgo, RJ. Revista Árvore, v. 30, n. 2, p.241-248, 2006. Disponível em: $<$ http://www.scielo.br/scielo.php?pid=S0100-

67622006000200011\&script=sci_abstract\&tlng=pt>. Acesso em: 22 Ago. 2019

CLEMENTE, Carlos Magno Santos; PEREIRA, Deborah Marques; LEAL, Thomas Leonardo Marques de Castro; REIS, Maycon Fagundes Teixeira. Análise espacial da precipitação pluviométrica na Microbacia do Rio Carnaíba de dentro e seu entorno no semiárido baiano entre 2009 a 2014. In: Caderno de Geografia, v.27, n.49, 2017. Disponível em:

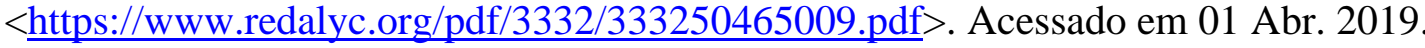

CREPANI, E.; MEDEIROS, J. S.; HERNANDEZ FILHO, P.; FLORENZANO, T. G.; DUARTE, V.; BARBOSA, C.C.F. Sensoriamento remoto e geoprocessamento aplicados ao zoneamento ecológico-econômico e ao ordenamento territorial. São José dos Campos: INPE, 124 p., 2001. Disponível em: <http://sap.ccst.inpe.br/artigos/CrepaneEtAl.pdf>. Acessado em 05 Jan. 2019.

COSTA, W. O. O sistema hídrico da comunidade Fazenda situada no maciço da Tijuca, Rio de Janeiro, RJ. Dissertação de mestrado apresentado ao Programa de Pós-Graduação da Universidade do Estado do Rio de Janeiro. 124p. 2017.

EMPRESA BRASILEIRA DE PESQUISA AGROPECUÁRIA (EMBRAPA). Manual de classificação dos solos. Brasília, CNPS, 1999. Disponível em: < https://livimagens.sct.embrapa.br/amostras/00053080.pdf>. Acessado em 12 Mar. 2019.

EMPRESA BRASILEIRA DE PESQUISA AGROPECUÁRIA (EMBRAPA). Levantamento Exploratório - Reconhecimento de solos da Margens direita e esquerda do Rio São Francisco Estado da Bahia. Embrapa Solos - UEP Recife. Recife, 1973.

GRIGORIEV, A. A. The theoretical fundaments o of modern physical geography. In: The interaction of sciences I the study of the earth. Moscou, 1968.

INSTITUTO BRASILEIRO DE GEOGRAFIA E ESTATÍSTICA - IBGE. Censo da população do Brasil, 2010. Disponível em: < http://www.ibge.gov.br/home>. Acessado em 14 Jan. 2019.

INSTITUTO BRASILEIRO DE GEOGRAFIA E ESTATÍSTICA - IBGE. Banco de Dados de Informações Ambientais, 2019. Disponível em: 〈https://bdiaweb.ibge.gov.br/\#/home〉. Acessado em 11 Set. 2019.

INSTITUTO BRASILEIRO DE GEOGRAFIA E ESTATÍSTICA - IBGE. Manual Técnico da Vegetação Brasileira, 2012. Disponível em: <https://biblioteca.ibge.gov.br/visualizacao/livros/liv63011.pdf $>$. Acessado em 17 Out. 2019.

LIMA, Daiane Fátima Batista de Lima, REMPEL, Claudete, ECKHARDT, Rafael Rodrigo. Análise ambiental da bacia hidrográfica do rio Taquari proposta de zoneamento ambiental.

V. 2, n.2, 2020 https://www.periodicos.unimontes.br/index.php/verdegrande 
Vulnerabilidade natural à perda de solo da microbacia hidrográfica do rio Carnaíba de Dentro, Semiárido Baiano

Jardel Gybson Soares Costa; Mateus R. Caetano; Carlos Magno Santos Clemente

GEOGRAFIA (Londrina), Londrina, 16, out. 2007. Disponível em: <http://www.uel.br/revistas/uel/index.php/geografia/article/view/6572/5966 > . Acesso em: 14 Jan. 2019.

PIRES, J. S. R; SANTOS, J. E.; DEL PRETTE, M. E. A utilização do conceito de bacia hidrográfica para a conservação dos recursos naturais. SCHIAVETTI, Alexandre; CAMARGO, Antônio F. M. (Edit.). In.: Conceitos de bacias hidrográficas: teorias e aplicações. $2^{\circ}$ ed. 293p. 2008.

REBOUÇAS, Aldo da C. Água na região Nordeste: desperdício e escassez. Estudos avançados. São Paulo. v.11, p.127-154, n 29, 1997. Disponível em <http://www.scielo.br/scielo.php?script=sci_arttext\&pid=S0103-40141997000100007>.

Acessado em 01 Out. 2019

RIBEIRO, M. A. Ecologizar: Pensando o Ambiente Humano. Belo Horizonte: Rona, 1998. 392p.

ROSA, R. Geotecnologias na Geografia aplicada. In: Revista do Departamento de Geografia, 2005. 81-90 p. Disponível em <http://www.revistas.usp.br/rdg/article/view/47288>. Acessado em 23 Jan. 2019

ROSA, Roberto. Introdução ao Geoprocessamento. UFU: Apostila. Uberlândia. 2013. 142 p. Disponível em: <http://professor.ufabc.edu.br/ flavia.feitosa/cursos/geo2016/AULA5ELEMENTOSMAPA/Apostila_Geop_rrosa.pdf>Acessado em 26 Jan. 2019

ROSS, Jurandyr Luciano Sanches. Análise empírica da fragilidade dos ambientes naturais e antropizados. In: Revista do Departamento de Geografia. n. 8, 63-74 p. 1994. Disponível em <http://www.revistas.usp.br/rdg/article/view/47327> Acessado em 26 Jan. 2019

RUELA, Bruno Parma. Caracterização morfométrica da Microbacia Bom Jardim situada no município de Rio Pomba, MG: Uma análise de áreas críticas para a possível implementação do Programa Produtor de Água. Dissertação de Mestrado apresentado ao Programa de Pós-Graduação em Geografia da Universidade Federal de Viçosa (UFV), Viçosa (MG), 2015.

SANTOS, Mílton. Metamorfoses do espaço habitado: fundamentos teóricos e metodológicos da Geografia. ReP-USP 6. ed. São Paulo: USP, 1996. Disponível em <https://bdpi.usp.br/single.php?_id=001171249> Acessado em 29 Mar. 2019

SANTOS, Mariana Rodrigues Ribeiro; RANIERI, Vitor Eduardo Lima. Critérios para análise do zoneamento como instrumento de planejamento e ordenamento territorial. In: Ambiente $\&$ Sociedade, 2013. 43-62p. Disponível em: < http://www.scielo.br/pdf/asoc/v16n4/04.pdf $>$. Acesso em: 06 Jan. 2019.

SOUZA, G.F et.al. Vulnerabilidade natural da paisagem em função das áreas de 
Vulnerabilidade natural à perda de solo da microbacia hidrográfica do rio Carnaíba de Dentro, Semiárido Baiano

Jardel Gybson Soares Costa; Mateus R. Caetano; Carlos Magno Santos Clemente

plantio de cana-de-açúcar. Revista GEOGRAFIA (Londrina) 19 ed. Londrina, 2010. Disponível em:

<http://www.uel.br/revistas/uel/index.php/geografia/> . Acesso em: 14 Jan. 2019.

SCHIAVETTI, Alexandre; CAMARGO, Antonio F. M. Conceitos de bacias hidrográficas teorias e aplicações ilhéus. Bahia: Editus, 2002. 293p. Disponível em: <http://www.uesc.br/editora/livrosdigitais2015/conceitos_de_bacias.pdf $>$. Acesso em: 18 Fev. 2019

VALERIANO, M. M.; ROSSETTI, D. F. Topodata: Brazilian full coverage refinement of SRTM data. Applied Geography (Sevenoaks), v. 32, p. 300-309, 2012.

TONELLO, Kelly Cristina et al. Morfometria da bacia hidrográfica da cachoeira das pombas, Guanhães - MG. Revista Árvore, Viçosa, v.30, n.5, p.849-857, 2006. Disponível em: $<$ http://www.scielo.br/scielo.php?pid=S0100-67622006000500019\&script=sci_abstract\&tlng $=\mathrm{pt}>$. Acesso em: 03 Jan. 2019.

THOMAS, Bruna Letícia. Proposta de zoneamento ambiental para o município de Arroio do Meio - RS. RAEGA - O Espaço Geográfico em Análise, v. 24, mar. 2012. ISSN 2177-2738. Disponível em: <http://dx.doi.org/10.5380/raega.v24i0.26215 >. Acesso em: 14 Jan. 2019.

TRICART Jean. Ecodinâmica. Rio de Janeiro: IBGE (SUPREN). 1977. 97 p. Disponível em: $<\quad$ https://biblioteca.ibge.gov.br/visualizacao/monografias/GEBIS\%20\%20RJ/ecodinamica.pdf>. Acesso em: 08 Jan. 2019.

TRICART, J. E KILIAN, J. L’éco-géographie. Librairie François Maspéro, col. Hérodote, 326 p. 1979.

WALLING, D.E.: WEBB, B.W. Erosion and sediment yield: a global view. In: International Association of Hydrological Sciences Publication. 1996. 236 p. Disponível em: <http://hydrologie.org/redbooks/a236/iahs_236_0003.pdf>. Acesso em: 08 Jan. 2019. 